\title{
An Overview of the Analytical Methods for the Determination of Organic Ultraviolet Filters in Cosmetic Products and Human Samples
}

\author{
Izabela Narloch (1) and Grażyna Wejnerowska *
}

Citation: Narloch, I.; Wejnerowska,

G. An Overview of the Analytical

Methods for the Determination of

Organic Ultraviolet Filters in

Cosmetic Products and Human

Samples. Molecules 2021, 26, 4780.

https://doi.org/10.3390/molecules

26164780

Academic Editor: Elena Falqué López

Received: 24 June 2021

Accepted: 3 August 2021

Published: 6 August 2021

Publisher's Note: MDPI stays neutral with regard to jurisdictional claims in published maps and institutional affiliations.

Copyright: (c) 2021 by the authors. Licensee MDPI, Basel, Switzerland. This article is an open access article distributed under the terms and conditions of the Creative Commons Attribution (CC BY) license (https:/ / creativecommons.org/licenses/by/ $4.0 /)$.
Department of Food Analysis and Environmental Protection, Faculty of Chemical Technology and Engineering, UTP University of Science and Technology, 3 Seminaryjna Street, 85-326 Bydgoszcz, Poland; izabela.narloch@utp.edu.pl

* Correspondence: grazyna.wejnerowska@utp.edu.pl; Tel.: +48-52-374-90-41

\begin{abstract}
UV filters are a group of compounds commonly used in different cosmetic products to absorb UV radiation. They are classified into a variety of chemical groups, such as benzophenones, salicylates, benzotriazoles, cinnamates, p-aminobenzoates, triazines, camphor derivatives, etc. Different tests have shown that some of these chemicals are absorbed through the skin and metabolised or bioaccumulated. These processes can cause negative health effects, including mutagenic and cancerogenic ones. Due to the absence of official monitoring protocols, there is an increased number of analytical methods that enable the determination of those compounds in cosmetic samples to ensure user safety, as well as in biological fluids and tissues samples, to obtain more information regarding their behaviour in the human body. This review aimed to show and discuss the published studies concerning analytical methods for the determination of organic UV filters in cosmetic and biological samples. It focused on sample preparation, analytical techniques, and analytical performance (limit of detection, accuracy, and repeatability).
\end{abstract}

Keywords: analytical methodologies; cosmetics products; human samples; organic ultraviolet filters; sample preparation

\section{Introduction}

In recent decades, there has been a progressive increase in UV radiation due to the depletion of the stratospheric ozone layer. This promotes an increase in the number of harmful effects on human health such as skin burns, skin photoaging, damage to the skin's immunological system, pterygium, or skin cancer [1,2]. Accordingly, the number of personal care products containing UV filters has increased rapidly to protect human skin from damaging exposure to sunlight. The currently estimated volume production of UV filters reaches 26.9 million tons [3]. UV filters are frequently added to all types of personal care products such as lotions, shampoos, creams, aftershave products, make-up products, etc. [4-6].

The European Union (EU) Regulation 1223/2009-Cosmetics Regulation defines UV filters as "substances which are exclusively or mainly intended to protect the skin against certain UV radiation by absorbing, reflecting or scattering UV radiation" [7]. UV filters are classified into two groups: organic (chemical) UV filters, which absorb UV light, as well as inorganic (physical) UV filters, which reflect and scatter UV radiation. Chemical UV filters are organic molecules capable of absorbing high UV-A and UV-B range radiation. The UV filters have one or more benzene rings and sometimes are conjugated with carbonyl groups [8]. They can be classified into different groups according to their chemical structure: benzophenone derivatives, p-aminobenzoic acid and its derivatives, salicylates, cinnamates, camphor derivatives, triazine derivatives, benzotriazole derivatives, benzimidazole derivatives, and others (Table 1) [9]. One of the most widely used family 
of UV filters are benzophenones, in particular BP-3, which in 2012 was classified by the US Environmental Protection Agency (US EPA) as "high production volume chemical" [3]. The scale of the problem of the existence of UV filters in the environment was presented by Astle et al. [3], who performed research among Swiss sunbathers on the use of UV filters during one tourist season. On their basis, it was estimated that about $1249 \mathrm{~kg}$ of ethylhexyl methoxycinnamate, $152 \mathrm{~kg}$ of octocrylene, $145 \mathrm{~kg}$ of $4-\mathrm{MBC}$, and $122 \mathrm{~kg}$ of avobenzene were released into Lake Zürich. Therefore, these compounds are the most frequently determined UV filters.

To protect consumers' health, the substances that can be used as UV filters in personal care products and their maximum allowed concentrations are strictly defined in each country [8]. The European Union regulations permit the use of 29 UV filters in cosmetics in concentrations ranging from 2 to $25 \%$ (Table 1). However, only two are inorganic (titanium dioxide and zinc oxide) [7]. Organic UV filters have a hydrophilic or lipophilic character and most of them are classified as water-resistant [8].

Despite the limitations on their use in UV filters, there are no established official analytical methods for the determination of these compounds in cosmetics products. However, to maintain the safety and adequate effectiveness of products containing UV filters, analytical methods should be developed to control the content of UV filters in them [10].

Moreover, due to the daily use of cosmetics containing UV filters, such compounds are absorbed through the skin into the body, where they can be metabolized and eventually bioaccumulated and/or excreted. The dermal absorption may result in harmful health effects like dermatitis but also more serious effects, such as mutagenic, cancerogenic, and/or estrogenic activity [11]. Therefore, because of the adverse effects of UV filters on human health and their potential bioaccumulation, such biological samples as urine, plasma, breast milk, semen, or tissues must be checked for their presence.

In this context, this review aimed to provide a comprehensive overview of the developments related to the determination of UV filters in cosmetic samples and biological fluids and tissues, with special emphasis on sample preparation and analytical techniques, as well as the achieved detection limits, accuracy, and repeatability.

\section{Analytical Methods for UV Filter Determination in Cosmetic Samples}

\subsection{Sample Preparation}

Cosmetic sample preparation depends on sample type, target analytes, and the technique that is to be used. In general, the preparation of a cosmetic sample does not require a complex pre-treatment sample. This is because the UV filter content in the cosmetic samples is at a sufficiently high level for the sample treatment not to require the extraction and concentration steps. Additionally, in most cases (approximately 90\%), liquid chromatography is used for analysis, which enables direct analysis of matrices such as cosmetics. It was alleged that in recent decades the methods of determining UV filters in cosmetics have not been modified too much [11,12].

The initial preparation of the sample consists of dissolving a cosmetic sample in a carefully selected solvent (typically ethanol, methanol, ethyl acetate, water, tetrahydrofuran). The step of dissolving the cosmetic sample may be preceded by homogenisation. Depending on the cosmetic product's type (i.e., consistency), the next steps in the procedure may include sonicating the sample for a few minutes $\left(5-30 \mathrm{~min}, 40^{\circ} \mathrm{C}\right)[10,13-33]$, magnetic mixing [34,35], mechanical shaking [20,36], vortexing (3-4 min), [25,29,32,37], or centrifuging (1-20 min, 3500-14,800 rpm) [14,19,20,25,27,29,32,33], which can help accelerate the solubilisation. The obtained supernatant is often filtered as well (e.g., $0.45 \mu \mathrm{m}$ nylon membrane filter) $[10,13-18,21-26,37]$ and/or evaporated $[19,25,27,29,33,38]$. 
Table 1. List of compounds that can be allowed as organic UV filters in cosmetic products according to the European Union legislation

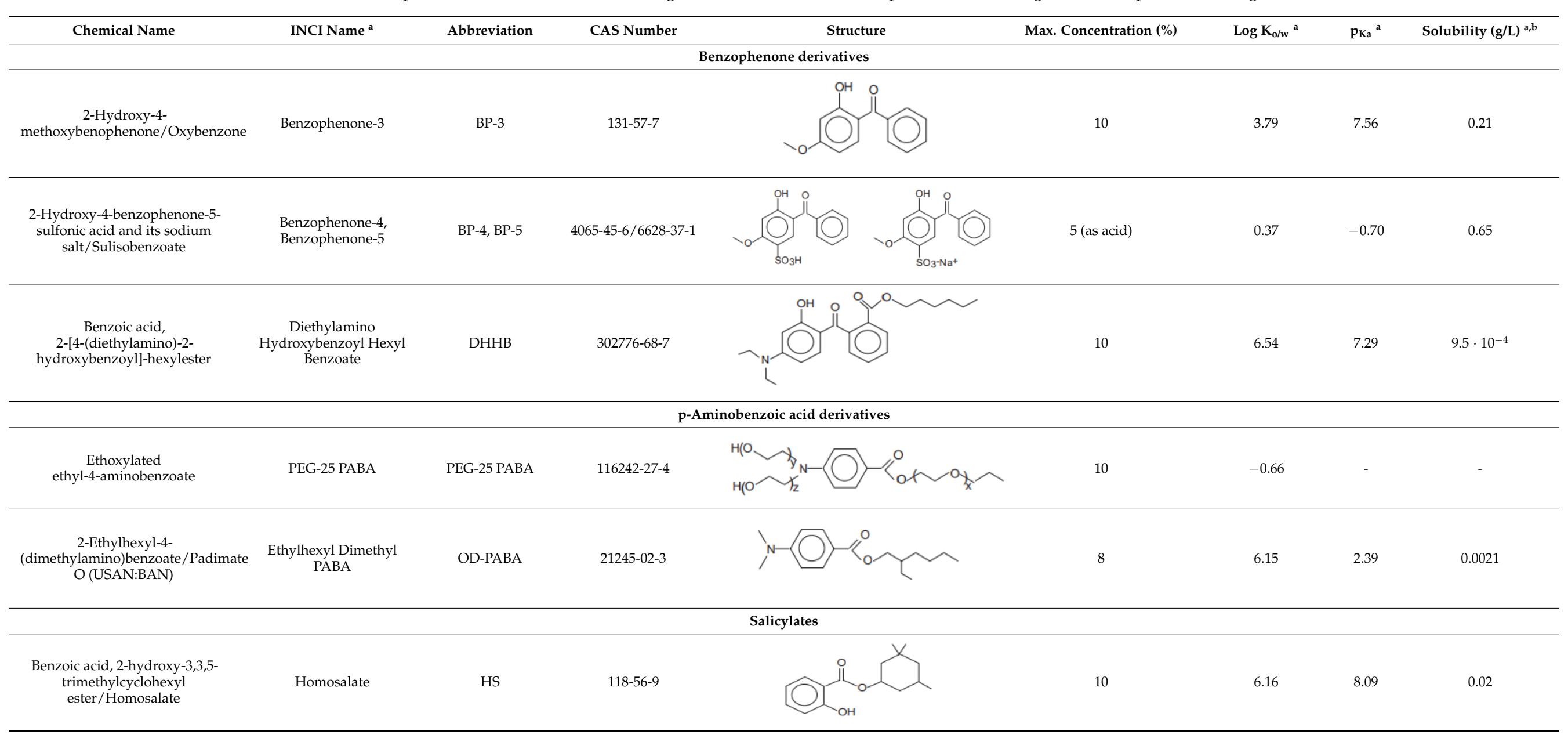


Table 1. Cont.

\begin{tabular}{|c|c|c|c|c|c|c|c|c|}
\hline Chemical Name & INCI Name $^{a}$ & Abbreviation & CAS Number & Structure & Max. Concentration (\%) & $\log K_{\mathrm{o} / \mathrm{w}}{ }^{\mathrm{a}}$ & $\mathrm{p}_{\mathrm{Ka}}{ }^{a}$ & Solubility $(g / L)^{a, b}$ \\
\hline $\begin{array}{c}\text { 2-Ethylhexyl } \\
\text { salicylate/Octisalate }\end{array}$ & Ethylhexyl Salicylate & EHS & $118-60-5$ & & 5 & 5.97 & 8.13 & 0.028 \\
\hline \multicolumn{9}{|c|}{ Cinnamates } \\
\hline $\begin{array}{l}\text { 2-Ethylhexyl-4- } \\
\text { methoxycinnamate/Octinoxate }\end{array}$ & $\begin{array}{c}\text { Ethylhexyl } \\
\text { Methoxycinnamate }\end{array}$ & OMC & $5466-77-3$ & & 10 & 5.8 & - & 0.15 \\
\hline $\begin{array}{l}\text { Isopentyl-4- } \\
\text { methoxycinnamate/Amiloxate }\end{array}$ & $\begin{array}{c}\text { Isoamyl } \\
\text { p-Methoxycinnamate }\end{array}$ & IMC & $71617-10-2$ & & 10 & 4.33 & - & 0.06 \\
\hline \multicolumn{9}{|c|}{ Benzimidazole derivatives } \\
\hline $\begin{array}{l}\text { 2-Phenylbenzimidazole-5- } \\
\text { sulfonic acid and its potassium, } \\
\text { sodium, and triethanolamine } \\
\text { salts/Ensulizole }\end{array}$ & $\begin{array}{l}\text { Phenylbenzimidazole } \\
\text { Sulfonic Acid }\end{array}$ & PMDSA & $27503-81-7$ & & 8 (as acid) & -0.16 & -0.87 & 0.26 \\
\hline $\begin{array}{c}\text { Sodium salt of } \\
\text { 2,2'-bis(1,4-phenylene)-1H- } \\
\text { benzimidazole-4,6-disulfonic } \\
\text { acid)/Bisdisulizole disodium } \\
\text { (USAN) }\end{array}$ & $\begin{array}{l}\text { Disodium Phenyl } \\
\text { Dibenzimidazole } \\
\text { Tetrasulfonate }\end{array}$ & DPDT & $180898-37-7$ & & 10 (as acid) & -6.79 & -0.27 & 0.5 \\
\hline \multicolumn{9}{|c|}{ Benzotriazole derivatives } \\
\hline $\begin{array}{l}\text { Phenol,2-(2H-benzotriazol-2-yl)- } \\
\text { 4-methyl-6-(2-methyl-3-(1,3,3,3- } \\
\text { tetramethyl-1- } \\
\text { (trimethylsilyl)oxy)- } \\
\text { disiloxanyl)propyl) }\end{array}$ & Drometrizole Trisiloxane & DTS & $155633-54-8$ & & 15 & 10.38 & 1.2 & $5.5 \cdot 10^{-10}$ \\
\hline
\end{tabular}


Table 1. Cont.

\begin{tabular}{|c|c|c|c|c|c|c|c|c|}
\hline Chemical Name & INCI Name $^{a}$ & Abbreviation & CAS Number & Structure & Max. Concentration (\%) & $\log K_{o / w}{ }^{a}$ & $\mathrm{p}_{\mathrm{Ka}}{ }^{\mathrm{a}}$ & Solubility $(g / L)^{a, b}$ \\
\hline $\begin{array}{c}\text { 2,2'-Methylene-bis }(6-(2 \mathrm{H}- \\
\text { benzotriazol-2-yl)-4-(1,1,3,3- } \\
\text { tetramethyl- } \\
\text { butyl)phenol)/Bisoctrizole }\end{array}$ & $\begin{array}{c}\text { Methylene } \\
\text { Bis-Benzotriazolyl } \\
\text { Tetramethylbutylphenol }\end{array}$ & MBP & $103597-45-1$ & & 10 & 12.46 & 7.56 & $3 \cdot 10^{-8}$ \\
\hline \multicolumn{9}{|c|}{ Camphor derivatives } \\
\hline $\begin{array}{l}\text { N,N,N-Trimethyl-4-(2-oxoborn-3- } \\
\text { ylidenemethyl)anilinium methyl } \\
\text { sulfate }\end{array}$ & $\begin{array}{l}\text { Camphor Benzalkonium } \\
\text { Methosulfate }\end{array}$ & CBM & 52793-97-2 & & 6 & 0.28 & - & 0.007 \\
\hline $\begin{array}{l}\text { 3,3'-(1,4-Phenylenedimethylene) } \\
\text { bis(7,7-dimethyl-2-oxobicyclo- } \\
{[2,2,1] \text { hept-1-yl-methanesu fonic }} \\
\text { acid) and its salts/Ecamsule }\end{array}$ & $\begin{array}{l}\text { Terephthalylidene } \\
\text { Dicamphor Sulfonic Acid }\end{array}$ & PDSA & $\begin{array}{l}92761-26-7, \\
90457-82-2\end{array}$ & & 10 (as acid) & 3.83 & -1.05 & 0.014 \\
\hline $\begin{array}{l}\text { Alpha-(2-Oxoborn-3-ylidene)- } \\
\text { toluene-4-sulphonic acid and its } \\
\text { salts }\end{array}$ & $\begin{array}{l}\text { Benzylidene Camphor } \\
\text { Sulfonic Acid }\end{array}$ & BCSA & 56039-58-8 & & 6 (as acid) & 2.22 & -0.7 & 0.038 \\
\hline $\begin{array}{l}\text { 3-(4-Methylbenzylidene)-d1 } \\
\text { camphor/Enzacamene }\end{array}$ & $\begin{array}{l}\text { 4-Methylbenzylidene } \\
\text { Camphor }\end{array}$ & $4-\mathrm{MBC}$ & $\begin{array}{l}38102-62-4 / \\
36861-47-9\end{array}$ & & 4 & 4.95 & - & 0.0051 \\
\hline
\end{tabular}


Table 1. Cont.

\begin{tabular}{|c|c|c|c|c|c|c|c|c|}
\hline Chemical Name & INCI Name ${ }^{a}$ & Abbreviation & CAS Number & Structure & Max. Concentration (\%) & $\log K_{\mathrm{o} / \mathrm{w}}{ }^{\mathrm{a}}$ & $\mathrm{p}_{\mathrm{Ka}}{ }^{\mathrm{a}}$ & Solubility $(g / L){ }^{a, b}$ \\
\hline $\begin{array}{c}\text { Polymer of } \mathrm{N}-\{(2 \text { and } \\
\text { 4)-[(2-oxoborn-3-ylidene)methyl- } \\
\text { ]benzyl }\} \\
\text { acrylamide }\end{array}$ & $\begin{array}{l}\text { Polyacrylamidomethyl } \\
\text { Benzylidene Camphor }\end{array}$ & РBC & $113783-61-2$ & & 6 & - & - & - \\
\hline \multicolumn{9}{|c|}{ Triazine derivatives } \\
\hline $\begin{array}{l}\text { Benzoic acid, 4,4-((6-((4-(((1,1- } \\
\text { dimethylethyl)amino)carbonyl) } \\
\text { phenyl)amino)-1,3,5-triazine-2,4- } \\
\text { diyl)diimino)bis-, bis } \\
\text { (2-ethylhexyl) ester/ Iscotrizinol } \\
\text { (USAN) }\end{array}$ & $\begin{array}{l}\text { Diethylhexyl Butamido } \\
\text { Triazone }\end{array}$ & DBT & $154702-15-5$ & & 10 & 14.03 & 3.04 & $4.6 \cdot 10^{-7}$ \\
\hline $\begin{array}{l}\text { 3,3'-(1,4-Phenylene)bis(5,6- } \\
\text { diphenyl-1,2,4-triazine) }\end{array}$ & $\begin{array}{l}\text { Phenylene Bis-Diphenyl } \\
\text { triazine }\end{array}$ & - & $55514-22-2$ & & 5 & - & - & - \\
\hline $\begin{array}{l}\text { 2,4,6-Trianilino-(p-carbo-2'- } \\
\text { ethylhexyl-1'-oxy)-1,3,5-triazine }\end{array}$ & Ethylhexyl Triazone & ET & $88122-99-0$ & & 5 & 17.05 & 3.17 & - \\
\hline $\begin{array}{l}\text { 2,2'-(6-(4-Methoxyphenyl)-1,3,5- } \\
\text { triazine-2,4-diyl)bis(5-(2- } \\
\text { ethylhexyl)oxy)phenol)/ } \\
\text { Bemotrizinol }\end{array}$ & $\begin{array}{l}\text { Bis-Ethylhexyloxyphenol } \\
\text { Methoxyphenyl Triazine }\end{array}$ & EMT & 187393-00-6 & & 10 & 8.03 & 6.37 & $4.9 \cdot 10^{-8}$ \\
\hline
\end{tabular}


Table 1. Cont.

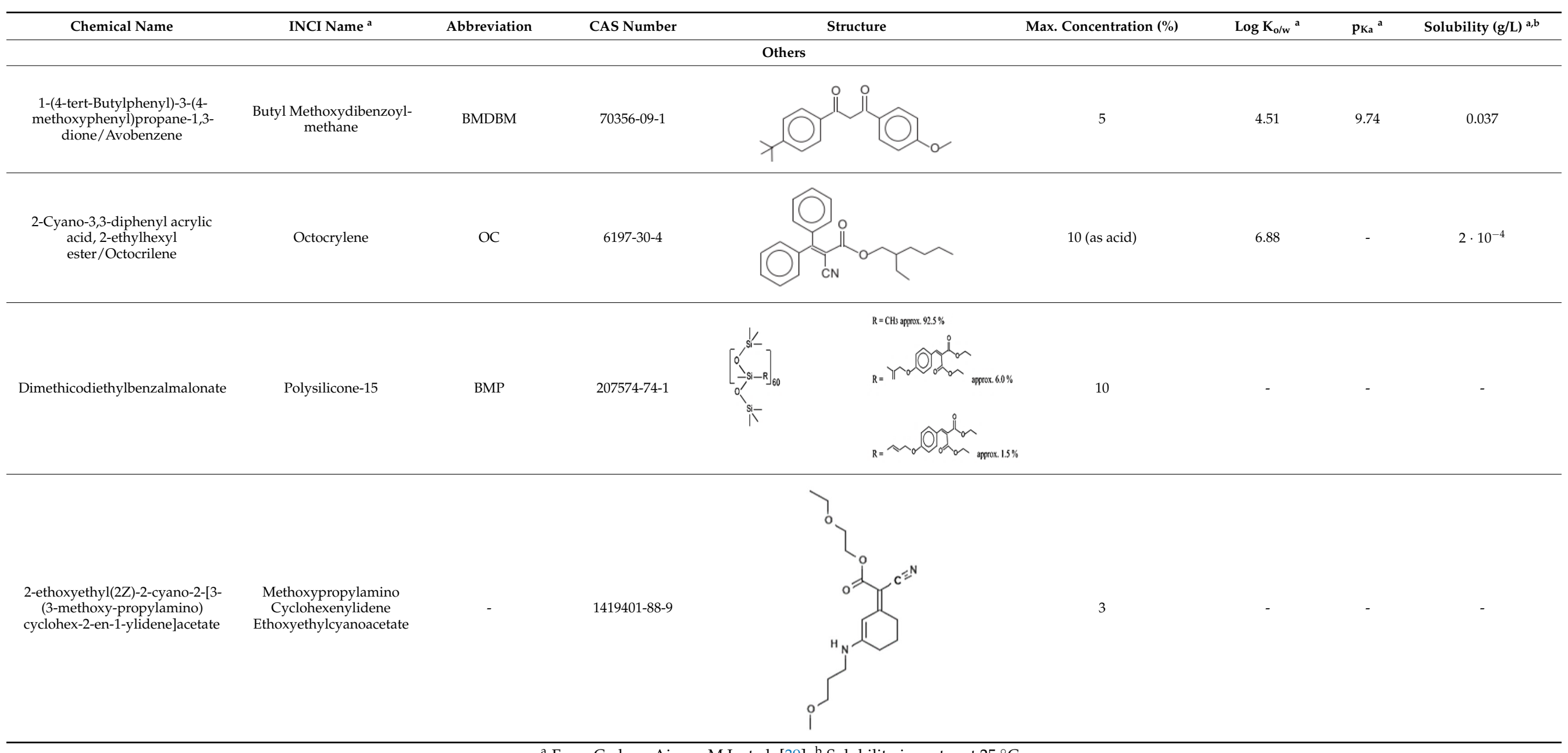


These procedures are aimed at completely dissolving the sample or leaching the target analytes (e.g., in case of difficult-to-dissolve samples such as wax-balms, lipsticks, or foundations containing insoluble compounds). The achieved high recoveries (Table 2), amounting from 80 to $113 \%$, confirm the effectiveness of these procedures.

Table 2. Published studies on UV filters determination in cosmetic samples.

\begin{tabular}{|c|c|c|c|c|}
\hline UV Filters & Matrix & Analytical Technique & Analytical Performance ${ }^{a}$ & Ref. \\
\hline $\begin{array}{l}\text { BP-3, IMC, MBC, DHHB, } \\
\text { OC, EDP, BDM, EMC, } \\
\text { EHS, HS, DBT, ET, DTS, } \\
\text { MBP, EMT }\end{array}$ & $\begin{array}{c}\text { Sunscreens, facial creams, } \\
\text { lip balms, aftershave } \\
\text { creams }\end{array}$ & $\begin{array}{c}\text { LC-UV/Vis; } \\
\text { type of column: } \mathrm{C}_{18} ; \\
\text { column temperature: } 60^{\circ} \mathrm{C} ; \\
\text { mobile phase: ethanol/formic acid (aq) } \\
\text { mobile phase modifier: } \\
\text { hydroxypropyl- } \beta \text {-cyclodextrin } \\
(\mathrm{HP}-\beta-\mathrm{CD})\end{array}$ & $\begin{array}{l}\text { LOD: } 0.02-0.22 \mu \mathrm{g} \mathrm{mL}^{-1} \\
\text { LOQ: } 0.07-0.74 \mu \mathrm{gL}^{-1} \\
\text { R: } 98-104 \% \\
\text { RSD: } 0.9-7.1 \%\end{array}$ & {$[10]$} \\
\hline $\begin{array}{c}\text { PMDSA, BP-4, BP-3, MBC, } \\
\text { DHHB, EMC, OC, MBP, } \\
\text { EMT, ET, BDM }\end{array}$ & Emulsion, oil & $\begin{array}{c}\text { HPLC-UV /Vis; } \\
\text { type of column: } \mathrm{C}_{8} \text { or } \mathrm{C}_{18} \text { or } \mathrm{C}_{16} ; \\
\text { column temp.: } 35^{\circ} \mathrm{C} ; \\
\text { mobile phase: gradient } \\
\text { acetonitrile/perchloric acid (aq) or } \\
\text { isocratic methanol/acetonitrile or } \\
\text { isocratic methanol/perchloric acid }\end{array}$ & $\begin{array}{l}\text { LOD: } 0.1-1.2 \mu \mathrm{g} \mathrm{mL} \mathrm{L}^{-1} \\
\text { LOQ: no data } \\
\text { R: } 93.9-103.4 \% \\
\text { RSD: } 0.2-1 \%\end{array}$ & {$[13]$} \\
\hline BP-1, BP-2, BP-3 & Emulsion & $\begin{array}{c}\text { MEKC-UV / Vis; } \\
\text { type of capillary: a } 51 \mathrm{~cm} \text { uncoated } \\
\text { fused-silica; } \\
\text { surfactant: sodium tetraborate } \\
\text { containing sodium dodecyl sulfate }\end{array}$ & $\begin{array}{c}\mathrm{LOD} 10^{-8}-3.90 \cdot 10^{-7} \mathrm{~mol} / \mathrm{L} \\
\text { LOQ: no data } \\
\text { R: } 89.5-102.5 \% \\
\text { RSD: } 1.14-8.09 \%\end{array}$ & [14] \\
\hline $\begin{array}{l}\text { PMDSA, PABA, BP-4, } \\
\text { BP-3, IMC, MBC, OC, } \\
\text { EMC, HS, EHS, MBBT }\end{array}$ & $\begin{array}{c}\text { Creams, lotions, } \\
\text { foundation, loose powder, } \\
\text { lipstick }\end{array}$ & $\begin{array}{c}\text { HPLC-UV/Vis; } \\
\text { type of column: } \mathrm{C}_{18} \\
\text { column temp.: } 30^{\circ} \mathrm{C} ; \\
\text { mobile phase: gradient } \\
\text { methanol/tetrahydrofuran/perchloric } \\
\text { acid (aq) }\end{array}$ & $\begin{array}{l}\text { LOD: } 200-500 \mathrm{ng} \mathrm{mL}^{-1} \\
\text { LOQ: } 700-6700 \mathrm{ng} \mathrm{mL}^{-1} \\
\text { R: } 98.5-102.2 \% \\
\text { RSD: } 0.51-1.72 \%\end{array}$ & {$[15]$} \\
\hline $\begin{array}{c}\text { PMDSA, BP-3, IMC, } \\
\text { DHHB, OC, EMC, EHS, } \\
\text { BDM, DBT, ET, MBP, EMT }\end{array}$ & Emulsion, sticks, powder & $\begin{array}{c}\text { HPLC-UV/Vis; } \\
\text { type of column: } \mathrm{C}_{18} \\
\text { column temp.: } 40^{\circ} \mathrm{C} \\
\text { mobile phase: gradient ethanol/ } \\
\text { 1\% phosphoric acid }(\mathrm{aq})\end{array}$ & $\begin{array}{l}\text { LOD: } 0.04-1.66 \mu \mathrm{g} \mathrm{mL}^{-1} \\
\text { LOQ: } 0.13-5.52 \mu \mathrm{g} \mathrm{mL}^{-1} \\
\text { R: } 97-101.4 \% \\
\text { RSD: } 0.38-2.42 \%\end{array}$ & [16] \\
\hline $\begin{array}{c}\text { HS, EDP, EHC, EHS, MBC, } \\
\text { BDM, BP-3, OC, PHBA, } \\
\text { BC }\end{array}$ & $\begin{array}{l}\text { Cream, milk, lotion, oil, } \\
\text { lipstick }\end{array}$ & DART-MS $\left(\mathrm{ESI}^{+}\right)$ & $\begin{array}{l}\text { LOD: } 2.5-460 \mu \mathrm{g} \mathrm{g}^{-1} \\
\text { LOQ: no data } \\
\text { R: } 71-120 \% \\
\text { RSD: } 4-30 \%\end{array}$ & [17] \\
\hline $\begin{array}{c}\text { EMC, IMC, EHS, MBC, } \\
\text { BP-3, EDP, OC, BDM }\end{array}$ & Cream, lotion, spray & $\begin{array}{c}\text { HPLC-UV/Vis; } \\
\text { type of column: } \mathrm{C}_{18} ; \\
\text { column temp.: } 30{ }^{\circ} \mathrm{C} ; \\
\text { mobile phase: gradient } \\
\text { acetonitrile/acetic acid (aq) }\end{array}$ & $\begin{array}{l}\text { LOD: } 0.03-1.5 \mathrm{mg} \mathrm{L}^{-1} \\
\text { LOQ: } 0.08-4.6 \mathrm{mg} \mathrm{L}^{-1} \\
\text { R: } 98-102 \% \\
\text { RSD: } 0.97-6.1 \%\end{array}$ & [18] \\
\hline $\begin{array}{c}\text { BP-4, BP-3, ODP, OMC, } \\
\text { EHS }\end{array}$ & $\begin{array}{l}\text { Cream, lotion, lipstick, } \\
\text { foundation }\end{array}$ & $\begin{array}{c}\text { HPLC-UV/Vis; } \\
\text { type of column: } \mathrm{C}_{18} ; \\
\text { column temp.: } 40^{\circ} \mathrm{C} ; \\
\text { mobile phase: gradient methanol/pure } \\
\text { water }(80: 20 ; v / v)\end{array}$ & $\begin{array}{l}\text { LOD: } 1-100 \mathrm{ng} \mathrm{L^{-1 }} \\
\text { LOQ: } 4-340 \mathrm{ng} \mathrm{L} \mathrm{L}^{-1} \\
\text { R: } 98-102 \% \\
\text { RSD: } 4-5.2 \%\end{array}$ & [19] \\
\hline OC & Emulsion & $\begin{array}{c}\text { SWV / mercury electrode; a mixture of } \\
\text { Britton-Robinson (BR) buffer and } \\
\text { ethanol }(7: 3 ; v / v) \text { as the supporting } \\
\text { electrolyte }\end{array}$ & $\begin{array}{l}\text { LOD: no data } \\
\text { LOQ: no data } \\
\text { R: } 9.7-106 \% \\
\text { RSD: } 1-3.42 \%\end{array}$ & [20] \\
\hline EMC, BP-3, EHS, OC & Emulsion & $\begin{array}{c}\text { LC-UV/Vis; } \\
\text { type of column: } \mathrm{C}_{18} ; \\
\text { mobile phase: methanol/water } \\
(85: 15 ; v / v)\end{array}$ & $\begin{array}{l}\text { LOD: no data } \\
\text { LOQ: no data } \\
\text { R: } 99.67-101 \% \\
\text { RSD: } 0.044-1.5 \%\end{array}$ & {$[21]$} \\
\hline
\end{tabular}


Table 2. Cont.

\begin{tabular}{|c|c|c|c|c|}
\hline UV Filters & Matrix & Analytical Technique & Analytical Performance ${ }^{a}$ & Ref. \\
\hline BDM, BP-3, EMC & Cream & $\begin{array}{c}\text { HPTLC-DS.; } \\
\text { type of column: } \mathrm{C}_{18 \text { or silica gel; }} \\
\text { mobile phase: acetonitrile/water (18:2) } \\
\text { or cyclohexane/diethyl } \\
\text { ether/n-hexane/acetone (14:2:1:2) }\end{array}$ & $\begin{array}{l}\text { LOD: no data } \\
\text { LOQ: no data } \\
\text { R: } 92.7-102.4 \% \\
\text { RSD: no data }\end{array}$ & [22] \\
\hline $\begin{array}{l}\text { PABA, PMDSA, BP-3, } \\
\text { MBC, BP-4, OC, EDP, } \\
\text { EMC, BDM, HS, EHS, } \\
\text { DBT, ET, DTS }\end{array}$ & Cream & $\begin{array}{c}\text { HPLC-UV/Vis; } \\
\text { type of column: } \mathrm{C}_{18} ; \\
\text { mobile phase: gradient } \\
\text { ethanol/phosphate buffer }\end{array}$ & $\begin{array}{l}\text { LOD: } 0.01-1.99 \mathrm{mg} \mathrm{L}^{-1} \\
\text { LOQ: } 0.02-6.02 \mathrm{mg} \mathrm{L}{ }^{-1} \\
\text { R: } 90.91-109.98 \% \\
\text { RSD: } 0.16-12.69 \%\end{array}$ & [23] \\
\hline $\mathrm{BP}-3, \mathrm{BP}-4$ & $\begin{array}{l}\text { Shampoo, gel, perfume, } \\
\text { cream }\end{array}$ & $\begin{array}{c}\text { MEKC-UV/Vis; } \\
\text { type of capillary: a } 64.5 \mathrm{~cm} \text { uncoated } \\
\text { fused-silica; } \\
\text { surfactant: sodium dodecyl sulphate }\end{array}$ & $\begin{array}{l}\text { LOD: } 0.91-2.26 \mu \mathrm{g} \mathrm{mL}^{-1} \\
\text { LOQ: } 2.72-6.79 \mu \mathrm{gL}^{-1} \\
\text { R: } 90.4-107.4 \% \\
\text { RSD: } 5.7-12 \%\end{array}$ & [24] \\
\hline $\begin{array}{c}\text { BP-1, BP-2, BP-3, BP-4, } \\
\text { BP-6, BP-8, OC, EMC, } \\
\text { PABA }\end{array}$ & Lotion, cream & $\begin{array}{c}\text { MEKC-UV/Vis; } \\
\text { type of capillary: a } 30.2 \mathrm{~cm} \text { uncoated } \\
\text { fused-silica; } \\
\text { surfactant: sodium dodecyl } \\
\text { sulfate } / \gamma \text {-cyclodextrin }\end{array}$ & $\begin{array}{l}\text { LOD: no data } \\
\text { LOQ: no data } \\
\text { R: } 95.08-104.57 \% \\
\text { RSD: no data }\end{array}$ & [25] \\
\hline $\begin{array}{c}\text { PABA, BP-3, IMC, MBC, } \\
\text { OC, EDP, EMC, BDM, } \\
\text { EHS, HS }\end{array}$ & Cream & $\begin{array}{c}\text { HPLC-UV/Vis; } \\
\text { type of column: } \mathrm{C}_{18} ; \\
\text { column temp.: } 35^{\circ} \mathrm{C} ; \\
\text { mobile phase: isocratic ethanol/acetic } \\
\text { acid (aq) }(70: 30 ; v / v)\end{array}$ & $\begin{array}{l}\text { LOD: } 0.1-2 \mu \mathrm{g} \mathrm{mL}^{-1} \\
\text { LOQ: } 0.5-5 \mu \mathrm{g} \mathrm{m}^{-1} \\
\text { R: no data } \\
\text { RSD: no data }\end{array}$ & [26] \\
\hline BP, BP-3, BP-1, HBP & Cream & $\begin{array}{c}\text { MEKC-UV/Vis; } \\
\text { type of capillary: a } 60 \mathrm{~cm} \text { uncoated } \\
\text { fused-silica; } \\
\text { surfactant: sodium dodecyl sulfate }\end{array}$ & $\begin{array}{l}\text { LOD: } 3.9-6.7 \mathrm{ng} \mathrm{mL}^{-1} \\
\text { LOQ: } 13-22.3 \mathrm{ng} \mathrm{mL}-1 \\
\text { R: } 80.2-117.7 \% \\
\text { RSD: no data }\end{array}$ & [27] \\
\hline $\begin{array}{l}\text { BP-3, EMC, OC, EHS, } \\
\text { MBC, EDP }\end{array}$ & $\begin{array}{l}\text { Cream, lipstick, blemish } \\
\text { balm cream }\end{array}$ & LTP-MS & $\begin{array}{l}\text { LOD: no data } \\
\text { LOQ: no data } \\
\text { R: no data } \\
\text { RSD: } 0.8-28.6 \%\end{array}$ & [28] \\
\hline $\begin{array}{l}\text { PMDSA, BP-2, BP-1, BP-8, } \\
\text { BP, BP-6, BP-3, EHS, BP-10, } \\
\text { HS, IMC, MBC, DHHB, } \\
\text { BDM, BP-12 }\end{array}$ & Lotion, cream, lipstick & $\begin{array}{c}\text { HPLC-MS/MS (ESI); } \\
\text { type of column: } \mathrm{C}_{18} ; \\
\text { column temp.: } 30^{\circ} \mathrm{C} ; \\
\text { mobile phase: gradient methanol } / 0.1 \% \\
\text { ammonium hydroxide }(\mathrm{aq})\end{array}$ & $\begin{array}{l}\text { LOD: } 2-20 \mathrm{mg} \mathrm{kg}^{-1} \\
\text { LOQ: } 5-50 \mathrm{mg} \mathrm{kg}^{-1} \\
\text { R: } 86.9-103.5 \% \\
\text { RSD: } 1-6.8 \%\end{array}$ & [29] \\
\hline $\begin{array}{c}\text { EHS, EMC, BP-3, OC, } \\
\text { EMT, BDM, DHHB, ET, } \\
\text { DBT }\end{array}$ & Cream & $\begin{array}{c}\text { UHPSFC-PDA; } \\
\text { type of column: Torus 2-PIC; } \\
\text { column temp.: } 40^{\circ} \mathrm{C} ; \\
\text { mobile phase: gradient } \\
\mathrm{CO}_{2} / \text { methanol/water/ammonium } \\
\text { acetate }\end{array}$ & $\begin{array}{l}\text { LOD: } 0.2-1.7 \mathrm{mg} \mathrm{kg}^{-1} \\
\text { LOQ: } 1-10.8 \mathrm{mg} \mathrm{kg} \\
\text { R: } 97.5-103.2 \% \\
\text { RSD: } 0.7-1.6 \%\end{array}$ & [30] \\
\hline $\begin{array}{c}\text { BP-1, BP-2, BP-3, BP-8, } \\
\text { HBP }\end{array}$ & $\begin{array}{c}\text { Toothpaste, shampoo, face } \\
\text { cleansers, sunscreens, } \\
\text { body lotions, gels, hair } \\
\text { gels,lotions, mask, hand } \\
\text { sanitizer }\end{array}$ & $\begin{array}{c}\text { HPLC-MS/MS }\left(\mathrm{ESI}^{-}\right) \\
\text {type of column: } \mathrm{C}_{18} ; \\
\text { column temp.: } 40{ }^{\circ} \mathrm{C} \\
\text { mobile phase: gradient } \\
\text { methanol/acetonitrile/water }\end{array}$ & $\begin{array}{c}\text { LOD: } 0.002-0.197 \mathrm{ng} \mathrm{mL}^{-1} \\
\text { LOQ: } 0.001-0.059 \mathrm{ng} \mathrm{mL}^{-1} \\
\text { R: } 61.9-116 \% \\
\text { RSD: no data }\end{array}$ & [31] \\
\hline BP-1 & Nail product & $\begin{array}{c}\text { GC-MS/MS }\left(\mathrm{EI}^{+}\right) ; \\
\text {type of column: } \mathrm{ZB}-\mathrm{SemiVolatiles} ; \\
\text { oven temp.: } 40^{\circ} \mathrm{C} / 2 \mathrm{~min}-5^{\circ} \mathrm{C} / 1 \mathrm{~min} \\
\text { to } 65^{\circ} \mathrm{C}-50^{\circ} \mathrm{C} / 1 \mathrm{~min} \text { to } \\
300^{\circ} \mathrm{C} / 5 \mathrm{~min}\end{array}$ & $\begin{array}{l}\text { LOD: } 18.3-2370 \mu \mathrm{g} \mathrm{g}^{-1} \\
\text { LOQ: no data } \\
\text { R: } 101-105 \% \\
\text { RSD: } 0.69-1.13 \%\end{array}$ & [32] \\
\hline BDM, EMT, OMC, OC, ET & Lotion & $\begin{array}{c}\text { HPLC-UV/Vis; } \\
\text { type of column: } \mathrm{C}_{18} ; \\
\text { mobile phase: acetonitrile/0.25\% } \\
\text { formic acid (aq) }\end{array}$ & $\begin{array}{l}\text { LOD: } 15 \mathrm{ng} \mathrm{mL}^{-1} \\
\text { LOQ: no data } \\
\text { R: } 88.1-104.7 \% \\
\text { RSD: } 0.8-5.4 \%\end{array}$ & [33] \\
\hline $\mathrm{BDM}$ & Emulsion & $\begin{array}{c}\text { LC-UV/Vis; } \\
\text { type of column: } \mathrm{C}_{18} ; \\
\text { column temp.: } 42{ }^{\circ} \mathrm{C} ; \\
\text { mobile phase: acetonitrile } / 0.5 \% \\
\text { phosphoric acid (aq) }\end{array}$ & $\begin{array}{c}\text { LOD: } 0.05796 \mu \mathrm{g} \mathrm{mL}^{-1} \\
\text { LOQ: } 0.19322 \mu \mathrm{g} \mathrm{mL}-1 \\
\text { R: no data } \\
\text { RSD: } 0.46-2.83 \%\end{array}$ & [34] \\
\hline
\end{tabular}


Table 2. Cont

\begin{tabular}{|c|c|c|c|c|}
\hline UV Filters & Matrix & Analytical Technique & Analytical Performance ${ }^{a}$ & Ref. \\
\hline $\begin{array}{l}\text { EMC, MBC, BP-1, BP-2, } \\
\text { BP-6, BP-4, OC, PABA, } \\
\text { EDP, EHS, HS, IMC, BP-3, } \\
\text { BP-8, BS, MA }\end{array}$ & $\begin{array}{l}\text { Cream, nail polish, } \\
\text { lipstick, hair gel }\end{array}$ & $\begin{array}{c}\text { GC-MS } / \mathrm{MS}\left(\mathrm{EI}^{+}\right) ; \\
\text {type of column: } \mathrm{SLB}-5 \mathrm{~ms} ; \\
\text { oven temp.: } 100^{\circ} \mathrm{C} / 1 \mathrm{~min}-25^{\circ} \mathrm{C} / \\
1 \mathrm{~min}-290^{\circ} \mathrm{C} / 5 \mathrm{~min}\end{array}$ & $\begin{array}{l}\text { LOD: } 0.0027-0.56 \mu \mathrm{g} \mathrm{g}^{-1} \\
\text { LOQ: } 0.009-1.9 \mu \mathrm{g} \mathrm{g}^{-1} \\
\text { R: } 37.4-110.5 \% \\
\text { RSD: } 3.9-9.1 \%\end{array}$ & [35] \\
\hline ET & Cream, lotion & $\begin{array}{c}\text { TLC-DS.; } \\
\text { type of layer: silica gel; } \\
\text { mobile phase: cyclohexanediethyl } \\
\text { ether }(1: 1)\end{array}$ & $\begin{array}{l}\text { LOD: } 0.03 \mu \mathrm{g} \mathrm{spot}^{-1} \\
\text { LOQ: } 0.1 \mu \mathrm{g} \mathrm{spot} \\
\text { R: } 95-105 \% \\
\text { RSD: } 4.5-5 \%\end{array}$ & [36] \\
\hline PMDSA, BDM, OC, EHS & Cream & $\begin{array}{c}\text { HTLC; } \\
\text { type of column: } \mathrm{C}_{18} ; \\
\text { column temp.: } 150-200{ }^{\circ} \mathrm{C} ; \\
\text { mobile phase: isocratic } \\
\text { methanol/water }\end{array}$ & $\begin{array}{l}\text { LOD: no data } \\
\text { LOQ: no data } \\
\text { R: } 90.3-113.2 \% \\
\text { RSD: } 2.8-5 \%\end{array}$ & [37] \\
\hline $\begin{array}{l}\text { EMC, MBC, BP-1, BP-2, } \\
\text { BP-6, BDM, BP-4, PMDSA, } \\
\text { MA, OC, EDP, IMC, BP-3, } \\
\text { BP-8, }\end{array}$ & $\begin{array}{c}\text { Lipsticks, hair gel, cream, } \\
\text { nail polish }\end{array}$ & $\begin{array}{c}\text { HPLC-MS/MS; } \\
\text { type of column: } \mathrm{C}_{18} ; \\
\text { oven temp.: } 30^{\circ} \mathrm{C} ; \\
\text { mobile phase: gradient methanol/0.1\% } \\
\text { formic acid/ammonia }(\mathrm{aq})\end{array}$ & $\begin{array}{c}\text { LOD: } 0.00039-0.031 \mu \mathrm{g} \mathrm{g}^{-1} \\
\text { LOQ: } 0.0013-0.1 \mu \mathrm{g} \mathrm{g}^{-1} \\
\text { R: } 81.7-102 \% \\
\text { RSD: } 4.5-13 \%\end{array}$ & [38] \\
\hline BDM, BP-3, EMC, EMT & Emulsion & $\begin{array}{c}\text { HPLC-UV/Vis; } \\
\text { type of column: } \mathrm{C}_{18} ; \\
\text { column temp.: } 25^{\circ} \mathrm{C} ; \\
\text { mobile phase: gradient } \\
\text { tetrahydfofuran/acetonitrile/acetic } \\
\text { acid (aq) }\end{array}$ & $\begin{array}{l}\text { LOD: no data } \\
\text { LOQ: no data } \\
\text { R: } 99.2-104.8 \% \\
\text { RSD: no data }\end{array}$ & [40] \\
\hline BP-4 & Shampoo & $\begin{array}{c}\text { TLC-UV/Vis; } \\
\text { type of layer: silica gel } 60 \text { plates; } \\
\text { mobile phase: } \\
\text { acetate/ethanol/water/phosphate } \\
\text { buffer }(15: 7: 5: 1 ; v / v / v / v)\end{array}$ & $\begin{array}{l}\text { LOD: } 0.03 \mu \mathrm{g} \mathrm{spot}{ }^{-1} \\
\text { LOQ: } 0.1 \mu \mathrm{g} \mathrm{spot}-1 \\
\text { R: } 100-103 \% \\
\text { RSD: } 0.58-1.99 \%\end{array}$ & [41] \\
\hline $\begin{array}{l}\text { EHS, EMC, BP-3, OC, } \\
\text { BDM, DHHB, ET, DBT }\end{array}$ & Cream & $\begin{array}{c}\text { SFC-UV/Vis; } \\
\text { type of column: } 2 \text {-ethyl pyridine; } \\
\text { column temp.: } 30{ }^{\circ} \mathrm{C} ; \\
\text { mobile phase: gradient } \\
\mathrm{CO}_{2} / \text { methanol/ethanol }(97: 1.5: 1.5)\end{array}$ & $\begin{array}{l}\text { LOD: no data } \\
\text { LOQ: no data } \\
\text { R: no data } \\
\text { RSD: } 0.6-2 \%\end{array}$ & [42] \\
\hline
\end{tabular}

a LOD and LOQ expressed as: $w / w$ when referred to sample or $w / v$ when referred to sample solution.

Despite the UV filters being the basic components of the samples, no special extraction techniques are needed. However, some authors proposed the use of extraction techniques such as pressurised liquid extraction [35,38], cloud point extraction [14], dispersive liquidliquid microextraction [27], or hollow fibre liquid-phase microextraction [19].

\subsection{Analytical Techniques}

Since the UV filters are part of the cosmetic products, their determination by direct measurement without a prior separation step is impossible. As such, chromatography methods are typically used. The most common chromatographic technique for determining UV filters is liquid chromatography; this is because UV filters have very high boiling points. In the majority of publications, the reversed-phase liquid chromatography coupled with a UV/Vis spectrometry detector with a single wavelength or with a diode-array is commonly used for this purpose. The application of a diode-array detector makes it possible to receive the whole UV spectrum for all peaks. The most used stationary phase is the traditional octadecylsilica type (C18), but octysilica (C8) and amide (C16) have been used as well [9]. In the case of reversed-phase separations, the most used solvents include water, methanol, tetrahydrofuran, acetonitrile, or their mixtures. The more environmentally friendly analytical methods include using the ethanol-water mixture in the mobile phase $[6,12,19,22]$. Isocratic or gradient elution modes are practised as well. Some substances can be added to the eluent to cut back peak tailing, such as acetic acid in the case of BP-3 $[14,35]$. Such reagents as phosphate, sodium acetate, and ammonium 
acetate are used for buffering. Hydroxypropyl- $\beta$-cyclodextrin is used as a mobile phase modifier to improve the resolution between varied analytes [6].

Therefore, gas chromatography is used in derivatization procedures with silylating reagents that can increase UV filter volatility, as well as sensitivity. Some publications $[32,35]$ describe the use of gas chromatography coupled with mass spectrometry with electron impact, with $\mathrm{N}, \mathrm{O}-\mathrm{Bis}$ (trimethylsilyl) trifluoroacetamide and acetic anhydrite used as the derivatizing reagents.

Apart from liquid and gas chromatography, there are also a few other separation techniques. One of them is micellar electrokinetic chromatography $[14,24,25,27]$, which utilises uncoated silica capillaries and sodium dodecyl sulphate as a surfactant. Others include thin-layer chromatography [22,36,37,41], supercritical fluid chromatography [30,42], and square wave voltammetry [20]. Table 2 shows the published reports on the determination of individual UV filters, including the sample preparation step and the analytical methodology, as well as the results obtained in terms of the limits of quantification, recovery method, and its precision.

\section{Analytical Methods for UV Filter Determination in Biological Samples}

Upon classifying published studies dealing with the determination of UV filters in human samples according to the studied matrix (Tables 3-5), it is clearly visible that the most studied biological matrix is urine $(\sim 61 \%)$, followed by blood, plasma, or serum $(\sim 20 \%)$. Other matrices such as milk ( $7 \%)$, tissues $(\sim 5 \%)$, and nail, semen, or saliva $(\sim 8 \%)$ have only been analysed intermittently (Figure 1$)$.

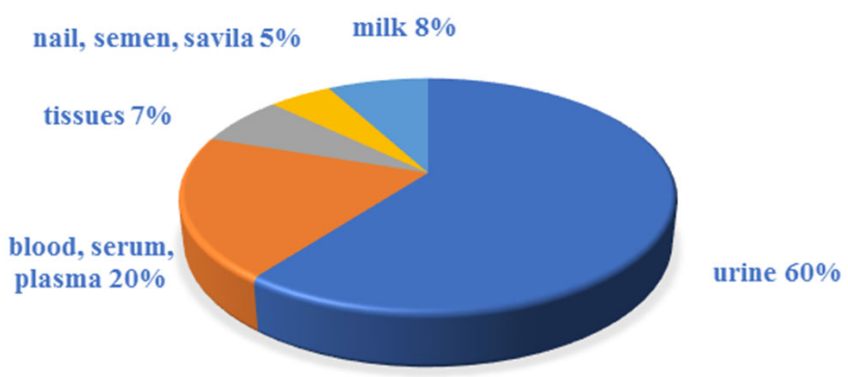

Figure 1. Biological sample types in the determination of UV filters.

To date, most research work is focused on the analysis of BP-3 and its metabolites, which have been widely determined in all types of biological samples. Other UV filters that have been analysed, albeit less often, include EMC, OMC, PABA, BDM, EDP, ES, HS, TDS, etc.

\subsection{Sample Preparation}

To determine UV filters in biological samples, the extraction $(\sim 75 \%)$ and microextraction $(\sim 25 \%)$ techniques have been used (Figure 2$)$. Extraction techniques include liquid-liquid extraction (LLE) ( 28\%), solid-phase extraction (SPE) $(\sim 28 \%)$, fabric phase sorptive extraction (FPSE) $(\sim 5 \%)$, as well as the less frequently used accelerated solvent extraction (ASE); microwave-assisted digestion/extraction (MAE); microporous membrane liquid-liquid extraction (MMLLE); matrix solid-phase dispersion (MSPD); sequential injection solid-phase extraction (SI SPE); Quick, Easy, Cheap, Effective, Rugged, and Safe Extraction (QuEChERSExtraction); solid-liquid extraction (SLE); ultrasound-assisted extraction (UAE); and ultrasound-assisted dispersive solid-phase extraction (USAD-SPE) (each $\sim 2 \%$ ). 


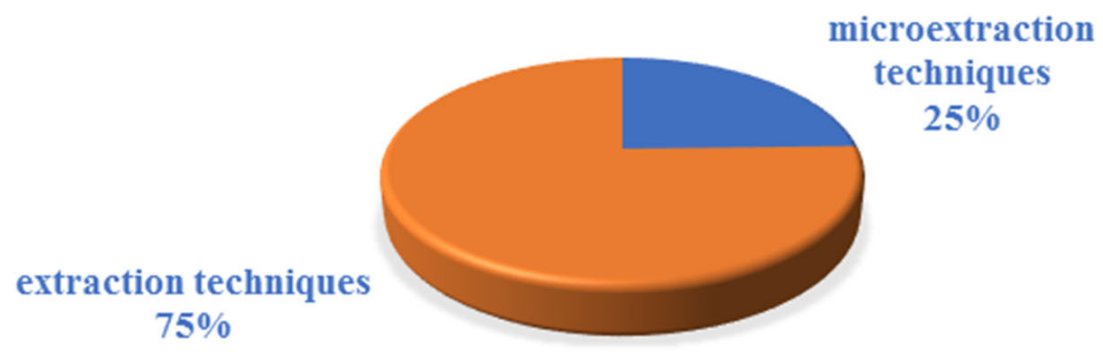

Figure 2. Division of analytical techniques into extraction and microextraction techniques.

In the last decades, a gradual increase in the use of microextraction methods for the isolation and enrichment of analytes in the tested samples has been observed. In the work of Jiménez-Díaz et al. from 2014 [43] on methods for determining UV filters in human samples, the contribution of microextraction methods was only about $7 \%$. Microextraction techniques include the dispersive liquid-liquid microextraction (DLLME) ( 10\%), as well as the less frequently employed air-assisted liquid-liquid microextraction (AALLME), bar adsorptive microextraction (BA $\mu \mathrm{E})$, hollow-fibre liquid-phase microextraction (HFLPME), microextraction by packed sorbent (MEPS), stir bar sorptive extraction (SBSE), single-drop microextraction (SDME), solid-phase microextraction (SPME), microextraction using a monolithic stirring extraction unit (MUMSEU), and vortex-assisted dispersive liquid-liquid microextraction (VADLLME) (each of them accounts for $2 \%$ ) (Figure 3).

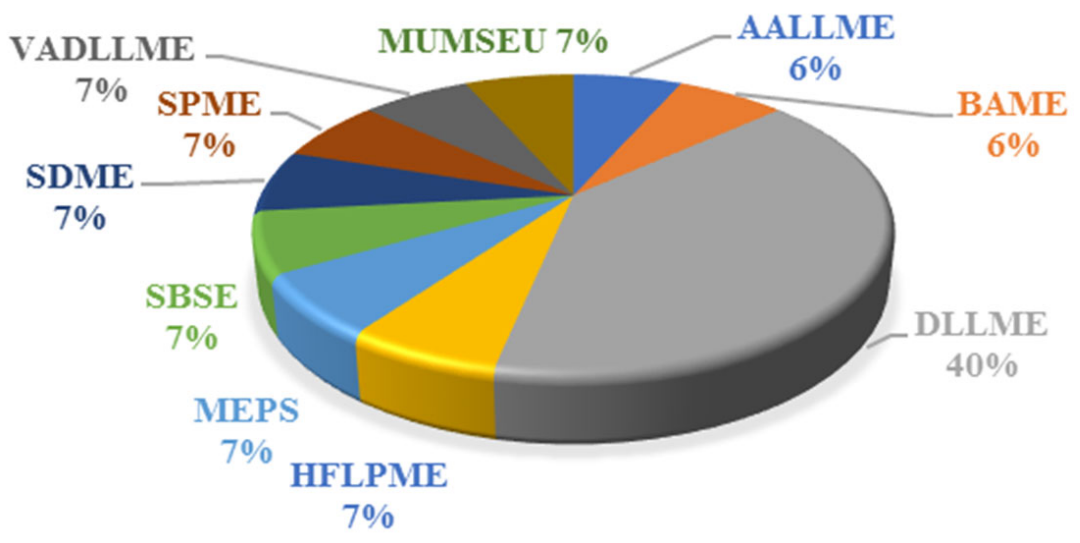

Figure 3. Microextraction techniques used for the determination of UV filters in biological samples.

Urine is the most frequently analysed sample. In urine, the compounds usually occur in free and conjugated forms; hydrolysis is often required to determine their total content (free plus conjugated). Without the hydrolysis step, it is only possible to determine the content of the free ones. The difference between free and conjugated content gives the total conjugated content. Older studies typically used $6 \mathrm{M}$ hydrochloric acid to hydrolyse the bounded compounds [44,45]. Today, enzymatic hydrolysis is achieved by incubating a urine sample with $\beta$-glucuronidase or with $\beta$-glucuronidase/sulfatase (under specific conditions such as $\mathrm{pH}$, temperature, and time) [46-68]. After enzymatic hydrolysis, the enzyme is denatured by treated with cold acetonitrile, methanol, or acetic acid to stop the reaction and then separated by centrifugation. The supernatant undergoes the next sample preparation step.

Table 3 summarises the extraction techniques used in the methods for determining UV filters in urine published in the literature. Liquid-liquid extraction (LLE) [51,55,57,58,63,66,69] and solid-phase extraction (SPE) $[46-50,56,59,62,64,65,70-72]$ are the most popular extraction techniques used to determine the UV filters. Accelerated solvent extraction (ASE) [62], 
fabric phase sorptive extraction (FPSE) [73], microporous membrane liquid-liquid extraction (MMLLE) [74], and sequential injection solid-phase extraction (SI SPE) [75] have been employed as well. However, microextraction techniques are also used to reduce solvent consumption and increase concentration factors. Microextraction techniques include airassisted liquid-liquid microextraction (AALLME) [68], bar adsorptive microextraction $(\mathrm{BA} \mu \mathrm{E})$ [76], dispersive liquid-liquid microextraction (DLLME) [61,77], hollow-fibre liquidphase microextraction (HFLPME) [55], microextraction by packed sorbent (MEPS) [78], stir bar sorptive extraction (SBSE) [53], single-drop microextraction (SDME) [52], solid-phase microextraction (SPME) [79], and vortex-assisted dispersive liquid-liquid microextraction (VADLLME) [67].

Table 3. Published papers on UV filters determination in urine.

\begin{tabular}{|c|c|c|c|c|c|}
\hline UV Filters & $\begin{array}{l}\text { Extraction } \\
\text { Technique }\end{array}$ & Analytical Technique & Analytical Performance & Comments & Ref. \\
\hline BP-3 & $\operatorname{SPE}\left(\mathrm{C}_{8}\right)$ & $\begin{array}{c}\text { HPLC-UV/Vis; } \\
\text { type of column: } \mathrm{C}_{18} \\
\text { mobile phase: isocratic } \\
\text { methanol/water }(70: 30)\end{array}$ & No data & Total content & [44] \\
\hline BP-3 & $\begin{array}{l}\text { SPE (Bond Elut } \\
\text { Certify LRC) }\end{array}$ & $\begin{array}{c}\left.\text { UPLC-MS/MS (ESI }{ }^{-}\right) \\
\text {type of column: Kinetex } \\
\text { Phenyl-Hexyl; } \\
\text { column temp.: } 35^{\circ} \mathrm{C} ; \\
\text { mobile phase: } \\
\text { water/acetonitrile/acetic acid }(\mathrm{aq})\end{array}$ & $\begin{array}{l}\text { LOD: } 0.3 \mathrm{ng} \mathrm{mL}-1 \\
\text { LOQ: } 0.61-200 \mathrm{ng} \mathrm{mL}^{-1} \\
\text { R: } 75.8-80.3 \% \\
\text { RSD: } 0.3-8 \%\end{array}$ & $\begin{array}{l}\text { Total and free } \\
\text { forms content }\end{array}$ & [46] \\
\hline $\mathrm{BP}-3$ & Online SPE $\left(\mathrm{RP}_{18}\right)$ & $\begin{array}{l}\text { HPLC-MS/MS }\left(\mathrm{APCI}^{-}\right) \\
\text {type of column: } \mathrm{RP}_{18} \\
\text { mobile phase: gradient } \\
\text { methanol/water }\end{array}$ & $\begin{array}{l}\text { LOD: } 0.3-0.5 \text { ng } \mathrm{mL}^{-1} \\
\text { LOQ: no data } \\
\text { R: } 97-105 \% \\
\text { RSD: } 1.7-20 \%\end{array}$ & $\begin{array}{c}\text { Total and } \\
\text { forms content }\end{array}$ & {$[47-49]$} \\
\hline BP-3 & $\operatorname{SPE}\left(\mathrm{C}_{18}\right)$ & $\begin{array}{c}\text { HPLC-MS (APCI); } \\
\text { type of column: C18-PFP; } \\
\text { mobile phase: methanol/water }\end{array}$ & $\begin{array}{l}\text { LOD: } 0.2 \text { ng } \mathrm{mL}^{-1} \\
\text { LOQ: no data } \\
\text { R: } 96 \% \\
\text { RSD: } 9.03-11.7 \%\end{array}$ & Total content & {$[50]$} \\
\hline $\begin{array}{c}\text { BP-1, BP-2, BP-8, } \\
\text { 4-OH-BP }\end{array}$ & $\begin{array}{c}\text { LLE (solvent: ethyl } \\
\text { acetate) }\end{array}$ & $\begin{array}{c}\text { HPLC-MS/MS }\left(\mathrm{ESI}^{+} / \mathrm{ESI}^{-}\right) \\
\text {type of column: } \mathrm{C}_{18} \\
\text { mobile phase: methanol/water }(90: 10 ; \\
v / v)\end{array}$ & $\begin{array}{c}\text { LOD: no data } \\
\text { LOQ: } 0.7-2.0 \mathrm{ng} \mathrm{mL} \mathrm{mL}^{-1} \\
\text { R: } 84-112 \% \\
\text { RSD: no data }\end{array}$ & Total content & [51] \\
\hline BP-3 & $\begin{array}{l}\text { SDME (acceptor } \\
\text { phase:[C6MIM][PF6]; } \\
25 \mathrm{~min} ; 900 \mathrm{rpm})\end{array}$ & $\begin{array}{c}\text { LC-UV; } \\
\text { type of column: } \mathrm{RP}_{18} \\
\text { mobile phase: ethanol } / 1 \% \text { acetic acid } \\
\text { aq }(60: 40 ; v / v)\end{array}$ & $\begin{array}{l}\text { LOD: } 1.3 \mathrm{ng} \mathrm{mL^{-1 }} \\
\text { LOQ: no data } \\
\text { R: no data } \\
\text { RSD: } 6 \%\end{array}$ & Free forms & [52] \\
\hline $\begin{array}{c}\text { BP, BP-OH, 2-OH-BP, } \\
\text { BP-3, BP-10 }\end{array}$ & $\begin{array}{l}\text { SBSE (PDMS; } 60 \\
\text { min; } 500 \mathrm{rpm} \text { ) }\end{array}$ & $\begin{array}{c}\text { GC-MS; } \\
\text { type of column: } \mathrm{DB}-5 \mathrm{~ms} \text {; } \\
\text { oven temp.: } 40^{\circ} \mathrm{C} / 1 \mathrm{~min}-5^{\circ} \mathrm{C} / \\
1 \mathrm{~min} \text { to } 190^{\circ} \mathrm{C}-15^{\circ} \mathrm{C} / \\
1 \mathrm{~min} \text { to } 280^{\circ} \mathrm{C} / 3 \mathrm{~min}\end{array}$ & $\begin{array}{l}\text { LOD: } 0.05-0.1 \mathrm{ng} \mathrm{mL} \mathrm{mL}^{-1} \\
\text { LOQ: } 0.2-0.5 \mathrm{ng} \mathrm{mL}^{-1} \\
\text { R: } 98.7-101.7 \% \\
\text { RSD: } 1.5-4.8 \%\end{array}$ & Free forms & [53] \\
\hline $\begin{array}{c}\text { BP, BP-OH, 2-OH-BP, } \\
\text { BP-3, BP-10 }\end{array}$ & $\begin{array}{l}\text { HFLPME (toluene; } \\
15 \text { min; } 500 \text { rpm) }\end{array}$ & $\begin{array}{l}\text { GC-MS (EI); } \\
\text { type of column: DB- } 5 \mathrm{~ms} ; \\
\text { oven temp.: } 40^{\circ} \mathrm{C} / 1 \mathrm{~min}-5^{\circ} \mathrm{C} / \\
1 \text { min to } 190^{\circ} \mathrm{C}-15^{\circ} \mathrm{C} / 1 \mathrm{~min} \text { to } \\
280^{\circ} \mathrm{C} / 4 \mathrm{~min}\end{array}$ & $\begin{array}{l}\text { LOD: } 5-10 \mathrm{pg} \mathrm{mL}^{-1} \\
\text { LOQ: } 20-50 \mathrm{pg} \mathrm{mL}^{-1} \\
\text { R: } 89.3-100.2 \% \\
\text { RSD: } 2.5-9.3 \%\end{array}$ & Total content & {$[54]$} \\
\hline $\begin{array}{c}\text { BP-1, BP-3, BP-8, } \\
\text { BP-2, 4-OH-BP }\end{array}$ & $\begin{array}{l}\text { LLE (solvent; } 50 \% \\
\text { MTBE/ethyl } \\
\text { acetate) }\end{array}$ & $\begin{array}{l}\text { HPLC-MS/MS }\left(\mathrm{ESI}^{-}\right) \\
\text {type of column: } \mathrm{C}_{18} \\
\text { mobile phase: gradient } \\
\text { methanol/water }\end{array}$ & $\begin{array}{l}\text { LOD: } 0.08-0.28 \mathrm{mg} \mathrm{mL}^{-1} \\
\text { LOQ: } 0.28-0.9 \mathrm{mg} \mathrm{mL}^{-1} \\
\text { R: } 85.2-99.6 \% \\
\text { RSD: } 2.8-4.5 \%\end{array}$ & Total content & [55] \\
\hline $\begin{array}{c}\text { BP-1, BP-3, BP-8, } \\
\text { THB }\end{array}$ & $\operatorname{SPE}\left(\mathrm{C}_{18}\right)$ & $\begin{array}{c}\text { LC-MS/MS }\left(\mathrm{ESI}^{+}\right) \\
\text {type of column: } \\
\text { Mediterranean SEA } 18 \\
\text { mobile phase: gradient } \\
\text { methanol/water } / 0.1 \% \text { formic acid aq }\end{array}$ & $\begin{array}{l}\text { LOD: } 1 \text { ng mL } \mathrm{mL}^{-1} \\
\text { LOQ: } 2-4 \mathrm{ng} \mathrm{mL}^{-1} \\
\text { R: } 84-111 \% \\
\text { RSD: no data }\end{array}$ & Total content & [56] \\
\hline
\end{tabular}


Table 3. Cont.

\begin{tabular}{|c|c|c|c|c|c|}
\hline UV Filters & $\begin{array}{l}\text { Extraction } \\
\text { Technique }\end{array}$ & Analytical Technique & Analytical Performance & Comments & Ref. \\
\hline $\begin{array}{l}\text { BP-1, BP-2, BP-3, } \\
\text { BP-8, 4-OH-BP }\end{array}$ & $\begin{array}{l}\text { LLE (solvent; } 50 \% \\
\text { MTBE/ethyl } \\
\text { acetate) }\end{array}$ & $\begin{array}{c}\text { HPLC-MS/MS (ESI); } \\
\text { type of column: } \mathrm{C}_{18} \\
\text { mobile phase: gradient methanol/water }\end{array}$ & $\begin{array}{c}\text { LOD: } 0.013-0.28 \mathrm{ng} \mathrm{mL}^{-1} \\
\text { LOQ: no data } \\
\text { R: } 85.2-99.6 \% \\
\text { RSD: } 1.4-4.5 \%\end{array}$ & Total content & [57] \\
\hline $\begin{array}{c}\text { BP-1, BP-2, BP-3, } \\
\text { BP-7, 4-OH-BP, } \\
\text { 4-MBP, 4-MBC, 3-BC }\end{array}$ & LLE & $\begin{array}{c}\text { On-line TurboFlow-LC-MS/MS; } \\
\text { type of column: TurboFlow Cyclone P } \\
\text { and Hypersil Gold aQ }\end{array}$ & $\begin{array}{l}\text { LOD: } 0.2-1.0 \mathrm{ng} \mathrm{mL}^{-1} \\
\text { LOQ: no data } \\
\text { R: } 77.1-108 \% \\
\text { RSD: } 5.7-15.1 \%\end{array}$ & $\begin{array}{l}\text { Total and free } \\
\text { form content }\end{array}$ & {$[58]$} \\
\hline EDP & $\begin{array}{l}\text { Automated SPE } \\
\qquad\left(\mathrm{C}_{18} \mathrm{HD}\right)\end{array}$ & $\begin{array}{c}\text { LC-MS/MS }\left(\mathrm{ESI}^{+}\right) \\
\text {type of column: Mediterranean SEA C } 18 \\
\text { mobile phase: gradient methanol/ } \\
\text { acetonitryle/water } / 0.2 \% \text { formic acid }\end{array}$ & $\begin{array}{l}\text { LOD: } 0.3-1.1 \mathrm{ng} \mathrm{mL}^{-1} \\
\text { LOQ: } 0.9-3.5 \mathrm{ng} \mathrm{mL} \mathrm{mL}^{-1} \\
\text { R: } 91-107 \% \\
\text { RSD: no data }\end{array}$ & $\begin{array}{l}\text { Total and free } \\
\text { forms content }\end{array}$ & [59] \\
\hline BP-3, OMC, OS, HS & $\begin{array}{l}\text { LLE (solvent: } \\
\text { acetonitrile) }\end{array}$ & $\begin{array}{c}\text { HPLC-DAD; } \\
\text { type of column: } \mathrm{C}_{18} \\
\text { mobile phase: gradient methanol/water } \\
(75: 25 ; v / v)\end{array}$ & $\begin{array}{l}\text { LOD: } 0.03-0.2 \mu \mathrm{g} \mathrm{mL}^{-1} \\
\text { LOQ: } 0.1-0.4 \mu \mathrm{gL}^{-1} \\
\text { R: } 86.8-92.2 \% \\
\text { RSD: } 3.0-4.4 \%\end{array}$ & Total content & {$[60]$} \\
\hline $\begin{array}{l}\text { BP-1, BP-2, BP-3, } \\
\text { BP-8, 4-OH-BP }\end{array}$ & $\begin{array}{l}\text { DLLME (disperser } \\
\text { solvent: acetone; } \\
\text { extraction solvent: } \\
\text { trichloromethane) }\end{array}$ & UHPLC-MS/MS & $\begin{array}{l}\text { LOD: } 0.1-0.2 \mathrm{ng} \mathrm{mL}^{-1} \\
\text { LOQ: } 0.3-0.6 \mathrm{ng} \mathrm{mL}^{-1} \\
\text { R: } 88-104 \% \\
\text { RSD: } 0.5-22.5 \%\end{array}$ & $\begin{array}{l}\text { Total and free } \\
\text { forms content }\end{array}$ & {$[61]$} \\
\hline BP-3, 4-MBC, HS, OC & ASE \& SPE & GC-MS/MS & $\begin{array}{l}\text { LOD: } 0.47-0.59 \mathrm{pg} \mathrm{mL} \mathrm{m}^{-1} \\
\text { LOQ: no data } \\
\text { R: } 70.5-110.7 \% \\
\text { RSD: }<5.04 \%\end{array}$ & $\begin{array}{l}\text { Total and free } \\
\text { forms content }\end{array}$ & {$[62]$} \\
\hline $\begin{array}{c}\text { BMDBM, } \\
\text { CDAA, EHS, } \\
\text { 5-OH-EHS, OC }\end{array}$ & $\begin{array}{l}\text { LLE (solvent: } \\
\text { actonitrile) }\end{array}$ & $\begin{array}{l}\text { LC-LC-MS/MS (ESI); } \\
\text { type of column: RP-18 ADS; }\end{array}$ & $\begin{array}{l}\text { LOD: } 0.1-1.5 \mu \mathrm{g} \mathrm{L}^{-1} \\
\text { LOQ: } 0.2-4.1 \mu \mathrm{g} \mathrm{L}^{-1} \\
\text { R: } 94.2-113.6 \% \\
\text { RSD: } 2.6-16.5 \%\end{array}$ & Total content & [63] \\
\hline $\begin{array}{c}\text { 5OH-EHS, 5oxo-EHS, } \\
\text { 5cx-EPS }\end{array}$ & $\begin{array}{l}\text { Online SPE } \\
\text { (TurboFlow } \\
\text { Phenyl) }\end{array}$ & $\begin{array}{c}\text { HPLC-MS/MS (ESI); } \\
\text { type of column: } \mathrm{C}_{18} ; \\
\text { mobile phase: gradient } \\
\text { acetonitryle/water } / 0.05 \% \text { acetic acid }\end{array}$ & $\begin{array}{c}\text { LOD: no data } \\
\text { LOQ: } 0.01-0.15 \mu \mathrm{g} \mathrm{L}^{-1} \\
\text { R: } 96-106 \% \\
\text { RSD: } 1.2-2.4 \%\end{array}$ & $\begin{array}{l}\text { Total and free } \\
\text { forms content }\end{array}$ & {$[64]$} \\
\hline BP-3 & Online SPE $\left(\mathrm{RP}_{18}\right)$ & $\begin{array}{c}\text { HPLC-MS/MS (ESI); } \\
\text { type of column: XDB-C } 18 ; \\
\text { mobile phase: gradient methanol/water }\end{array}$ & $\begin{array}{l}\text { LOD: } 0.16 \mu \mathrm{g} \mathrm{L}^{-1} \\
\text { LOQ: no data } \\
\text { R: } 101 \% \\
\text { RSD: } 5 \% \\
\end{array}$ & $\begin{array}{l}\text { Total and free } \\
\text { forms content }\end{array}$ & [65] \\
\hline $\begin{array}{l}\text { BP-1, BP-2, BP-3, } \\
\text { BP-8, 4-OH-BP }\end{array}$ & $\begin{array}{l}\text { LLE (solvent: } \\
\text { ethyl tert-butyl } \\
\text { ether/ethyl } \\
\text { acetate }(5: 1 ; v: v))\end{array}$ & $\begin{array}{c}\text { UHPLC-TQMS }\left(\mathrm{ESI}^{-}\right) \\
\text {type of column: } \mathrm{C}_{18} ; \\
\text { column temp.: } 30^{\circ} \mathrm{C} ; \\
\text { mobile phase: water/acetonitrile }\end{array}$ & $\begin{array}{c}\text { LOD: } 0.01-0.2 \mathrm{ng} \mathrm{mL} \mathrm{m}^{-1} \\
\text { LOQ: no data } \\
\text { R: } 90.7-110.1 \% \\
\text { RSD: } 6.9-14.2 \% \\
\end{array}$ & $\begin{array}{l}\text { Total and free } \\
\text { forms content }\end{array}$ & {$[66]$} \\
\hline $\begin{array}{l}\text { BP-1, BP-2, BP-3, } \\
\text { BP-8, 4-OH-BP }\end{array}$ & $\begin{array}{l}\text { VADLLME } \\
\text { (disperser solvent: } \\
\text { 2-propanol; } \\
\text { extraction solvent: } \\
\text { dichloromethane) }\end{array}$ & $\begin{array}{c}\text { LC-MS/MS; } \\
\text { type of column: } \mathrm{C}_{18} ; \\
\text { column temp.: } 23^{\circ} \mathrm{C} ; \\
\text { mobile phase: water } / \text { methanol }\end{array}$ & $\begin{array}{l}\text { LOD: } 0.02-0.03 \mathrm{ng} \mathrm{mL}^{-1} \\
\text { LOQ: } 0.05-0.4 \mathrm{ng} \mathrm{mL} \mathrm{mL}^{-1} \\
\text { R: no data } \\
\text { RSD: } 1.2-12 \%\end{array}$ & Total content & {$[67]$} \\
\hline $\begin{array}{l}\text { BP-1, BP-2, BP-3, } \\
\text { BP-8, 4-OH-BP }\end{array}$ & $\begin{array}{c}\text { AALLME } \\
\text { (extraction } \\
\text { solvent: } 1,2- \\
\text { dichloroethane) }\end{array}$ & $\begin{array}{c}\text { LC-MS/MS (ESI); } \\
\text { type of column: } \mathrm{C}_{18} ; \\
\text { column temp.: } 40^{\circ} \mathrm{C} ; \\
\text { mobile phase: water /methanol }\end{array}$ & $\begin{array}{l}\text { LOD: } 0.02-0.06 \mathrm{ng} \mathrm{mL}^{-1} \\
\text { LOQ: } 0.05-0.20 \mathrm{ng} \mathrm{mL}^{-1} \\
\text { R: no data } \\
\text { RSD: }<15 \%\end{array}$ & Total content & {$[68]$} \\
\hline $\begin{array}{l}\text { PABA, 4-AHA, } \\
\text { 4-AMB, } \\
\text { 4- } \mathrm{OCH}_{3}-\mathrm{AHA}\end{array}$ & $\begin{array}{l}\text { LLE \& SPE } \\
\text { (solvent: ethyl } \\
\text { acetate; } \mathrm{C}_{18} \text { ) }\end{array}$ & $\begin{array}{c}\text { HPLC-ECD; } \\
\text { type of column: } \mathrm{C}_{18} ; \\
\text { mobile phase: methanol/phosphate } \\
\text { buffer }(\mathrm{pH} 5.5)(20: 80 ; v / v)\end{array}$ & $\begin{array}{c}\text { LOD: no data } \\
\text { LOQ: } 0.04-0.18 \mathrm{ng} \mathrm{mL}^{-1} \\
\text { R: } 96-99 \% \\
\text { RSD: } 0.2-3.8 \%\end{array}$ & Total content & [69] \\
\hline BP-1, BP-3 & $\operatorname{SPE}\left(\mathrm{C}_{8}\right)$ & $\begin{array}{c}\text { HPLC-UV; } \\
\text { type of column: } \mathrm{C}_{18} ; \\
\text { mobile phase: acetonitryle/water }\end{array}$ & $\begin{array}{l}\text { LOD: } 2-40 \mathrm{ng} \mathrm{mL}-1 \\
\text { LOQ: no data } \\
\text { R: no data } \\
\text { RSD: } 6.6-13 \%\end{array}$ & $\begin{array}{l}\text { Total and free } \\
\text { form content }\end{array}$ & {$[70]$} \\
\hline
\end{tabular}


Table 3. Cont.

\begin{tabular}{|c|c|c|c|c|c|}
\hline UV Filters & Extraction Technique & Analytical Technique & Analytical Performance & Comments & Ref. \\
\hline PMDSA & Online SPE & SIA-FL & $\begin{array}{l}\text { LOD: } 12 \mathrm{ng} \mathrm{mL}-1 \\
\text { LOQ: no data } \\
\text { R: no data } \\
\text { RSD: } 2-13 \%\end{array}$ & Free forms & [71] \\
\hline PEG-25 PABA & $\operatorname{SPE}\left(C_{18}\right)$ & $\begin{array}{l}\text { LC-FL; } \\
\text { mobile phase: dimethylfuran }\end{array}$ & $\begin{array}{l}\text { LOD: } 2.6 \mathrm{ng} \mathrm{mL} \mathrm{mL}^{-1} \\
\text { LOQ: no data } \\
\text { R: } 91-100 \% \\
\text { RSD: } 3-10 \%\end{array}$ & Total content & [72] \\
\hline $\begin{array}{l}\text { BP-4, 4-DHB, BP-2, } \\
\text { BP-1, BP-8, BZ }\end{array}$ & FPSE & $\begin{array}{c}\text { HPLC-PDA; } \\
\text { type of column: } \mathrm{C}_{18} \\
\text { mobile phase: methanol/phosphate } \\
\text { buffer }(\mathrm{pH} 3)(45: 55 ; v / v)\end{array}$ & $\begin{array}{l}\text { LOD: } 0.03 \mu \mathrm{g} \mathrm{mL}^{-1} \\
\text { LOQ: } 0.1 \mu \mathrm{g} \mathrm{mL}^{-1} \\
\text { R: no data } \\
\text { RSD: } 2.3-14.4 \%\end{array}$ & Total content & [73] \\
\hline EDP & $\begin{array}{c}\text { In-vial MMLLE } \\
\text { (hydrophobic PTFE } \\
\text { membranes) }\end{array}$ & $\begin{array}{c}\text { GC-MS; } \\
\text { type of column: SPB-5; } \\
\text { oven temp.: } 60^{\circ} \mathrm{C} / 1.5 \mathrm{~min}- \\
30^{\circ} \mathrm{C} / 1 \mathrm{~min} \text { to } 275^{\circ} \mathrm{C} / 20 \mathrm{~min}\end{array}$ & $\begin{array}{l}\text { LOD: no data } \\
\text { LOQ: } 0.11 \mu \mathrm{g} \mathrm{L}^{-1} \\
\text { R: no data } \\
\text { RSD: } 7.4 \%\end{array}$ & Total content & [74] \\
\hline BP-3, BP-4 & $\begin{array}{c}\text { SI SPE ( } \mathrm{C}_{18} \text { and } \\
\text { diethylaminopropyl) }\end{array}$ & $\begin{array}{c}\mathrm{LC} / \mathrm{UV} ; \\
\text { type of column: } \mathrm{RP}_{18} \\
\text { mobile phase: ethanol/acetate } \\
\text { buffer } / 1 \% \text { acetic acid }\end{array}$ & $\begin{array}{l}\text { LOD: } 30-60 \mathrm{ng} \mathrm{mL}-1 \\
\text { LOQ: no data } \\
\text { R: no data } \\
\text { RSD: } 6-13 \%\end{array}$ & Free forms & [75] \\
\hline $\begin{array}{c}\text { BP-1, BP-2, } \\
\text { BP-8, 4-OH-BP }\end{array}$ & $\operatorname{MEPS}\left(\mathrm{C}_{18}\right)$ & $\begin{array}{l}\text { LC-MS/MS; } \\
\text { mobile phase: water/methanol }\end{array}$ & $\begin{array}{c}\text { LOD: } 0.005-0.03 \mathrm{ng} \mathrm{mL}^{-1} \\
\text { LOQ: } 0.02-0.10 \mathrm{ng} \mathrm{mL}^{-1} \\
\text { R: } 18-118 \% \\
\text { RSD: } 1-16 \%\end{array}$ & $\begin{array}{l}\text { Total and free } \\
\text { forms content }\end{array}$ & [78] \\
\hline ВР-1, ВР-3, ВР-8 & $\begin{array}{c}\text { SPME } \\
\text { (Carbowax/DVB) }\end{array}$ & $\begin{array}{c}\text { GC-MS; } \\
\text { type of column: DB5-MS; } \\
\text { Oven temp.: } 50^{\circ} \mathrm{C} / 0.1 \mathrm{~min}-30^{\circ} \mathrm{C} / \\
1 \text { min to } 150^{\circ} \mathrm{C}-18^{\circ} \mathrm{C} / 1 \mathrm{~min} \text { to } \\
250^{\circ} \mathrm{C} / 12 \mathrm{~min}\end{array}$ & $\begin{array}{l}\text { LOD: } 5-10 \mathrm{ng} \mathrm{mL} \mathrm{L}^{-1} \\
\text { LOQ: no data } \\
\text { R: no data } \\
\text { RSD: } 5-8 \%\end{array}$ & Total content & [79] \\
\hline $\begin{array}{l}\text { BP, BP-1, BP-3, } \\
\text { 4-OH-BP }\end{array}$ & $\mathrm{BA} \mu \mathrm{E}$ & $\begin{array}{c}\text { HPLC-DAD; } \\
\text { type of column: Sea-18; } \\
\text { mobile phase: methanol/water } \\
(75: 25 ; v / v)\end{array}$ & $\begin{array}{l}\text { LOD(P2): }<1.0 \mu \mathrm{g} \mathrm{L}^{-1} \\
\text { LOQ(P2): }<0.3 \mu \mathrm{g} \mathrm{L}^{-1} \\
\text { LOD(AC4): }<1.3 \mu \mathrm{g} \mathrm{L}^{-1} \\
\text { LOQ(AC4): }<0.4 \mu \mathrm{g} \mathrm{L}^{-1}\end{array}$ & Total content & [76] \\
\hline $\begin{array}{c}\text { OMC, BP-3, OC, OS, } \\
\text { HS }\end{array}$ & $\begin{array}{l}\text { DLLME (disperser } \\
\text { solvent: carbon } \\
\text { tetrachloride; } \\
\text { extraction solvent: } \\
\text { acetonitrile) }\end{array}$ & $\begin{array}{c}\text { HPLC-DAD; } \\
\text { type of column: } \mathrm{C}_{18} ; \\
\text { mobile phase: isocratic } \\
\text { water/methanol/acetonitrile } \\
(8: 42: 50 ; v / v / v)\end{array}$ & $\begin{array}{l}\text { LOD: no data } \\
\text { LOQ: } 3-45 \mathrm{ng} \mathrm{mL} \mathrm{m}^{-1} \\
\text { R: } 86.9-97.3 \% \\
\text { RSD: } 0.1-6.4 \%\end{array}$ & Total content & [77] \\
\hline $\begin{array}{l}\text { BP-1, BP-2, BP-3, } \\
\text { BP-8, 4-OH-BP }\end{array}$ & $\begin{array}{l}\text { Microextraction using a } \\
\text { monolithic stirring } \\
\text { extraction unit } \\
(150 \mathrm{~min} ; 1100 \mathrm{rpm})\end{array}$ & $\begin{array}{l}\text { UPLC-DAD; } \\
\text { mobile phase: acetonitrile/water }\end{array}$ & $\begin{array}{l}\text { LOD: } 1-10 \mu \mathrm{g} \mathrm{L}^{-1} \\
\text { LOQ: } 5-20 \mu \mathrm{g} \mathrm{L}^{-1} \\
\text { R: } 71-114 \% \\
\text { RSD: } 5.6-9.1 \%\end{array}$ & Total content & [80] \\
\hline
\end{tabular}

The liquid-liquid extraction is a time-consuming technique, which requires large volumes of organic solvents, and is not automated. It uses different types of organic solvents such as ethyl acetate, a mixture of methyl tert-butyl ether: ethyl acetate, ethanol, methanol, and acetonitrile. The solid-phase extraction is used in manual mode or an online configuration or in commercially available automated workstations. Octadecyl silica sorbents (C18) are widely used for UV filter analysis using SPE in manual mode; divinylbenzene/Nvinylpyrrolidone copolymer (HLB) is an alternative option in this regard. The microextraction techniques are based on the equilibrium processes. Additionally, solid-phase microextraction (SPME) is based on the division of the analyte between the urine sample and a sorbent such as carbowax-DVB fibre. Stir-bar sorptive extraction (SBSE) uses the polymer coating of polydimethylsiloxane as a sorbent. Another microextraction technique is the microextraction by packed sorbent (MEPS), which uses the C18 sorbent to extract analytes. Yet another technique is the dispersive liquid-liquid microextraction (DLLME), which uses solvents (dispersing—acetone and extracting — trichloromethane). Different microextraction methods include hollow-fibre liquid-phase microextraction (HFLPME), 
based on the use of polypropylene porous hollow fibre, air-assisted liquid-liquid microextraction (AALLME), bar adsorptive microextraction $(\mathrm{BA} \mu \mathrm{E})$, single-drop microextraction (SDME), and vortex-assisted dispersive liquid-liquid microextraction (VADLLME). The final steps are attaining lyophilisation and redissolution of the residue in the solvent.

When examining plasma or serum, blood must undergo additional treatment to isolate them (Table 4). Plasma also includes large proteins such as albumin or immunoglobulin. Such treatment consists in the centrifugation of fresh blood with the addition of an anticoagulant. Serum, however, is prepared by centrifuging blood samples without anticoagulant. To determinate the total compound content, the hydrolysis step must be performed with either acid [81] or an enzyme solution [82-85]. In the case of blood, serum, or plasma samples, protein precipitation is commonly used to reduce matrix interferences. This is performed by mixing the sample with such organic solvents as acetonitrile $[60,63,86]$, methanol $[73,81]$, acetone [83], or formic acid [84,85]. Proteins are denatured, precipitated, and separated through centrifugation.

Table 4. Published studies on UV filters determination in blood, plasma, and serum.

\begin{tabular}{|c|c|c|c|c|c|c|}
\hline UV Filters & Matrix & $\begin{array}{l}\text { Extraction } \\
\text { Technique }\end{array}$ & Analytical Technique & Analytical Performance & Comments & Ref. \\
\hline BP-3, BP-1, BP-8 & Serum & $\begin{array}{l}\text { DLLME (disperser } \\
\text { solvent: acetone: } \\
\text { extraction solvent: } \\
\text { chloroform) }\end{array}$ & $\begin{array}{c}\text { LC-MS/MS }\left(\mathrm{ESI}^{+}\right) ; \\
\text {type of column: } \mathrm{C}_{18} ; \\
\text { mobile phase: gradient } \\
\text { methanol/water } / 0.1 \% \\
\text { formic acid }\end{array}$ & $\begin{array}{l}\text { LOD: } 7-8 \mu \mathrm{g} \mathrm{L}^{-1} \\
\text { LOQ: } 22-28 \mu \mathrm{g} \mathrm{L}^{-1} \\
\text { R: } 77-104 \% \\
\text { RSD: } 8-9 \%\end{array}$ & Total content & [45] \\
\hline $\begin{array}{c}\text { BP-3, OMC, OS, } \\
\text { HS }\end{array}$ & Plasma & $\begin{array}{l}\text { LLE (solvent: } \\
\text { acetonitrile) }\end{array}$ & $\begin{array}{c}\text { HPLC-DAD; } \\
\text { type of column: } \mathrm{C}_{18} \\
\text { mobile phase: gradient } \\
\text { methanol/water }(75: 25 ; v / v)\end{array}$ & $\begin{array}{c}\text { LOD: } 0.03-0.2 \mu \mathrm{g} \mathrm{mL}^{-1} \\
\text { LOQ: } 0.1-0.4 \mu \mathrm{g} \mathrm{mL}^{-1} \\
\text { R: } 90.8-103.8 \% \\
\text { RSD: } 2.1-4.4 \%\end{array}$ & Total content & [60] \\
\hline $\begin{array}{l}\mathrm{BP}-3, \mathrm{OMC}, \mathrm{OS} \\
\mathrm{HS}\end{array}$ & $\begin{array}{l}\text { Bovine } \\
\text { serum } \\
\text { albumin }\end{array}$ & $\begin{array}{l}\text { LLE (solvent; } \\
\text { acetonitrile) }\end{array}$ & $\begin{array}{c}\text { HPLC-DAD; } \\
\text { type of column: } \mathrm{C}_{18} ; \\
\text { mobile phase: gradient } \\
\text { methanol/ water } \\
(75: 25 ; v / v)\end{array}$ & $\begin{array}{c}\text { LOD: } 0.03-0.2 \mu \mathrm{g} \mathrm{mL}^{-1} \\
\text { LOQ: } 0.1-0.4 \mu \mathrm{g} \mathrm{mL}-1 \\
\text { R: } 97.9-102.3 \% \\
\text { RSD: } 1.2-3.3 \%\end{array}$ & Total content & {$[60]$} \\
\hline $\begin{array}{c}\text { BP-1, BP-2, BP-3, } \\
\text { BP-6, BP-8, } \\
\text { 4-OH-BP }\end{array}$ & $\begin{array}{l}\text { Menstrual } \\
\text { blood }\end{array}$ & $\begin{array}{l}\text { DLLME (disperser } \\
\text { solvent: acetone; } \\
\text { extraction solvent: } \\
\text { trichloromethane) }\end{array}$ & $\begin{array}{l}\text { UHPLC-MS/MS (ESI); } \\
\text { type of column: } \mathrm{C}_{18}\end{array}$ & $\begin{array}{l}\text { LOD: } 0.2-0.3 \mathrm{ng} \mathrm{mL} \mathrm{m}^{-1} \\
\text { LOQ: no data } \\
\text { R: no data } \\
\text { RSD: } 0.28-1.59 \%\end{array}$ & $\begin{array}{l}\text { Total and } \\
\text { free forms } \\
\text { content }\end{array}$ & [82] \\
\hline $\begin{array}{c}\text { BP-1, BP-2, BP-3, } \\
\text { BP-6, BP-8, } \\
\text { 4-OH-BP }\end{array}$ & Serum & $\begin{array}{l}\text { DLLME (disperser } \\
\text { solvent: acetone; } \\
\text { extraction solvent: } \\
\text { trichloromethane) }\end{array}$ & $\begin{array}{c}\text { UPLC-MS/MS }\left(\mathrm{ESI}^{+}\right) \\
\text {type of column: } \mathrm{C}_{18} ; \\
\text { mobile phase: gradient } 0.1 \% \\
\text { ammoniacal aq } / 0.1 \% \\
\text { ammonia in methanol }\end{array}$ & $\begin{array}{l}\text { LOD: } 0.1-0.3 \mathrm{ng} \mathrm{mL} \mathrm{m}^{-1} \\
\text { LOQ: } 0.4-0.9 \mathrm{ng} \mathrm{mL}-1 \\
\text { R: } 97-106 \% \\
\text { RSD: } 1.9-13.7 \%\end{array}$ & $\begin{array}{l}\text { Total and } \\
\text { free forms } \\
\text { content }\end{array}$ & [83] \\
\hline BP-3 & Serum & Online SPE & HPLC-MS/MS (APPI') & $\begin{array}{l}\text { LOD: } 0.5 \mathrm{ng} \mathrm{mL}-1 \\
\text { LOQ: no data } \\
\text { R: } 96 \% \\
\text { RSD: } 7.7-8.7 \%\end{array}$ & Total content & {$[84,85]$} \\
\hline $\begin{array}{l}\text { OC, BMDBM, } \\
\text { CDAA }\end{array}$ & Plasma & $\begin{array}{l}\text { LLE (solvent: } \\
\text { acetonitrile) }\end{array}$ & $\begin{array}{l}\text { LC-LC-MS/MS (ESI); } \\
\text { type of column: } \mathrm{C}_{18} \\
\text { mobile phase: } \\
\text { methanol/water }\end{array}$ & $\begin{array}{l}\text { LOD: } 1.1-6.5 \mu \mathrm{g} \mathrm{L}^{-1} \\
\text { LOQ: } 3.5-20.7 \mu \mathrm{g} \mathrm{L}^{-1} \\
\text { R: } 89.0-112.8 \% \\
\text { RSD: } 3.0-4.9 \%\end{array}$ & Total content & [63] \\
\hline BP-3 & Plasma & $\begin{array}{l}\text { LLE (solvent: } \\
\text { acetonitrile) }\end{array}$ & $\begin{array}{l}\text { UHPLC-DAD; } \\
\text { type of column: } \mathrm{C}_{18} ; \\
\text { mobile phase: } \\
\text { acetonitrile/water }\end{array}$ & $\begin{array}{l}\text { LOD: no data } \\
\text { LOQ: no data } \\
\text { R: } 94-99 \% \\
\text { RSD: } 2.3-4.6 \%\end{array}$ & Total content & [86] \\
\hline $\begin{array}{c}\text { BP-4, 4-DHB, } \\
\text { BP-2, BP-1, BP-8, } \\
\text { BZ }\end{array}$ & Whole blood & FPSE & $\begin{array}{c}\text { HPLC-PDA; } \\
\text { type of column: } \mathrm{C}_{18} \\
\text { mobile phase: } \\
\text { methanol/phosphate buffer } \\
(\mathrm{pH} 3)(45: 55 ; v / v)\end{array}$ & $\begin{array}{l}\text { LOD: } 0.03 \mu \mathrm{g} \mathrm{mL}^{-1} \\
\text { LOQ: } 0.1 \mu \mathrm{g} \mathrm{mL} \\
\text { R: no data } \\
\text { RSD: } 0.4-10.8 \%\end{array}$ & Total content & [73] \\
\hline
\end{tabular}


Table 4. Cont.

\begin{tabular}{|c|c|c|c|c|c|c|}
\hline UV Filters & Matrix & $\begin{array}{l}\text { Extraction } \\
\text { Technique }\end{array}$ & Analytical Technique & Analytical Performance & Comments & Ref. \\
\hline $\begin{array}{c}\text { BP-4, 4-DHB, } \\
\text { BP-2, BP-1, BP-8, } \\
\text { BZ }\end{array}$ & Plasma & FPSE & $\begin{array}{c}\text { HPLC-PDA; } \\
\text { type of column: } \mathrm{C}_{18} \\
\text { mobile phase: } \\
\text { methanol/phosphate buffer } \\
(\mathrm{pH} 3)(45: 55 ; v / v)\end{array}$ & $\begin{array}{l}\text { LOD: } 0.03 \mu \mathrm{g} \mathrm{mL}^{-1} \\
\text { LOQ: } 0.1 \mu \mathrm{g} \mathrm{mL}^{-1} \\
\text { R: no data } \\
\text { RSD: } 3.6-11.1 \%\end{array}$ & Total content & [73] \\
\hline $\begin{array}{c}\text { BP-3, BP-1, } \\
\text { 4-OH-BP, BP-8, } \\
\text { 4-DHB, BP-2, } \\
\text { BP-4, BMDBM }\end{array}$ & $\begin{array}{l}\text { Umbilical } \\
\text { cord blood }\end{array}$ & LLE (solvent: MTBE) & $\begin{array}{l}\text { LC-MS/MS }\left(\mathrm{ESI}^{+} ; \mathrm{ESI}^{-}\right) \\
\text {type of column: } \mathrm{R}_{18} ; \\
\text { mobile phase: } \\
\text { methanol/water }\end{array}$ & $\begin{array}{l}\text { LOD: } 0.05-0.42 \mathrm{ng} \mathrm{mL}^{-1} \\
\text { LOQ: } 0.18-1.39 \mathrm{ng} \mathrm{mL}^{-1} \\
\text { R: } 14.3-146.4 \% \\
\text { RSD: } 0.5-33.8 \%\end{array}$ & Total content & [81] \\
\hline BP, 4-MBP & Plasma & $\begin{array}{l}\text { LLE-SPE (solvent: } \\
\text { MTBE; Oasis } \\
\text { Prime-HLB) }\end{array}$ & $\begin{array}{l}\text { HPLC-MS/MS (ESI); } \\
\text { type of column: } \mathrm{C}_{18} ; \\
\text { mobile phase: } 0.1 \% \text { formic } \\
\text { acid in water } / 0.1 \% \text { formic } \\
\text { acid in methanol }\end{array}$ & $\begin{array}{c}\text { LOD: } 0.8-2 \mathrm{pg} \mathrm{mL}^{1} \\
\text { LOQ: } 3.5-7 \mathrm{pg} \mathrm{mL} \mathrm{m}^{-1} \\
\text { R: } 87-97 \% \\
\text { RSD: } 3.1-9.1 \%\end{array}$ & Total content & [87] \\
\hline
\end{tabular}

Table 5. Published studies on UV filters determination in semen, saliva, milk, nail, and placental tissue.

\begin{tabular}{|c|c|c|c|c|c|c|}
\hline UV Filters & Matrix & Extraction Technique & Analytical Technique & Analytical Performance & Comments & Ref. \\
\hline $\begin{array}{c}\text { BP-1, BP-3, BP-8, } \\
\text { THB }\end{array}$ & Semen & $\operatorname{SPE}\left(C_{18}\right)$ & $\begin{array}{l}\text { LC-MS/MS }\left(\mathrm{ESI}^{+}\right) \text {; } \\
\text { type of column: Mediterranean SEA } 18 \text {; } \\
\text { mobile phase: gradient mobile phase: } \\
0.1 \% \text { formic acid in water } / 0.1 \% \text { formic } \\
\text { acid in methanol }\end{array}$ & $\begin{array}{l}\text { LOD: } 0.03-0.04 \mathrm{ng} \mathrm{mL}^{-1} \\
\text { LOQ: } 0.08-0.13 \mathrm{ng} \mathrm{mL}^{-1} \\
\text { R: } 98-115 \% \\
\text { RSD: no data }\end{array}$ & Total content & [56] \\
\hline BP-3, OMC, OS, HS & $\begin{array}{l}\text { Epidermal } \\
\text { membranes }\end{array}$ & $\begin{array}{l}\text { LLE (solvent: } \\
\text { acetonitrile) }\end{array}$ & $\begin{array}{c}\text { HPLC-DAD; } \\
\text { type of column: } \mathrm{C}_{18} ; \\
\text { mobile phase: gradient } \\
\text { methanol/water }(75: 25 ; v / v)\end{array}$ & $\begin{array}{l}\text { LOD: } 0.03-0.2 \mu \mathrm{g} \mathrm{mL}^{-1} \\
\text { LOQ: } 0.1-0.4 \mu \mathrm{g} \mathrm{mL}^{-1} \\
\text { R: } 98.5-99.5 \% \\
\text { RSD: } 1.8-3.2 \%\end{array}$ & Total content & {$[60]$} \\
\hline $\begin{array}{l}\text { OC, 3-BC, } 4 \mathrm{MBC}, \\
\text { OMC, EDP, BP-1, } \\
\text { BP-3, BP-6, BP-8, } \\
\text { 4-OH-BP }\end{array}$ & Milk & $\begin{array}{l}\text { QuEChERS Extraction; } \\
\text { SALLE \& d-SPE } \\
\text { (sorbent: polysecondary } \\
\text { amine and magnesium } \\
\text { sulphate) }\end{array}$ & $\begin{array}{c}\text { UHPLC-MS/MS (API); } \\
\text { type of column: } \mathrm{C}_{18} ; \\
\text { mobile phase: gradient } \\
\text { acetonirile/water } / 0.1 \% \text { formic acid }\end{array}$ & $\begin{array}{l}\text { LOD: } 0.1-0.2 \mathrm{ng} \mathrm{mL}^{1} \\
\text { LOQ: } 0.4-0.6 \mathrm{ng} \mathrm{mL} \mathrm{mL}^{-1} \\
\text { R: } 87-112 \% \\
\text { RSD: } 8-14 \%\end{array}$ & Total content & [88] \\
\hline BP-3 & Breast milk & Online SPE $\left(\mathrm{RP}_{18}\right)$ & $\begin{array}{l}\text { HPLC-MS/MS }\left(\mathrm{APCI}^{-}\right) \\
\text {type of column: } \mathrm{RP}_{18} \\
\text { mobile phase: gradient } \\
\text { methanol/water }\end{array}$ & $\begin{array}{l}\text { LOD: } 0.51 \mathrm{ng} \mathrm{mL} \mathrm{mL}^{-1} \\
\text { LOQ: no data } \\
\text { R: } 94.7 \% \\
\text { RSD: } 12.7-18 \%\end{array}$ & $\begin{array}{l}\text { Total and } \\
\text { free forms } \\
\text { content }\end{array}$ & [89] \\
\hline $\begin{array}{c}\text { BP-1, BP-3, } \\
\text { 4-OH-BP, 4DHB, } \\
\text { 4MBC, ODPABA, } \\
\text { EtPABA, TBHPBT }\end{array}$ & Breast milk & Online TFC & $\begin{array}{c}\text { HPLC-MS/MS (ESI); } \\
\text { type of column: Cyclone and } \mathrm{C}_{18} \\
\text { mobile phase: gradient } \\
\text { methanol/water } / 0.1 \% \text { formic acid }\end{array}$ & $\begin{array}{l}\text { LOD: } 0.1-1.5 \mathrm{ng} \mathrm{g}^{-1} \\
\text { LOQ: } 0.3-5.1 \mathrm{ng} \mathrm{g}^{-1} \\
\text { R: no data } \\
\text { RSD: } 1-12 \%\end{array}$ & Total content & [90] \\
\hline BP-3 & Milk & Online SPE $\left(\mathrm{RP}_{18}\right)$ & $\begin{array}{c}\text { HPLC-MS/MS }\left(\mathrm{APCI}^{-}\right) \\
\text {type of column: } \mathrm{RP}_{18} ; \\
\text { mobile phase: methanol/water }\end{array}$ & $\begin{array}{l}\text { LOD: } 0.4 \mathrm{ng} \mathrm{mL} \mathrm{m}^{-1} \\
\text { LOQ: no data } \\
\text { R: } 102 \% \\
\text { RSD: } 8.8-12 \%\end{array}$ & $\begin{array}{l}\text { Total and } \\
\text { free forms } \\
\text { content }\end{array}$ & [91] \\
\hline $\begin{array}{l}\text { BP-1, BP-3, BP-6, } \\
\text { BP-8, 4-OH-BP }\end{array}$ & Breast milk & $\begin{array}{l}\text { USAD-SPE ( } 15 \text { min of } \\
\text { sonification; sorbents: } \\
\mathrm{C}_{18} \text {, polysecondary } \\
\text { amine and magnesium } \\
\text { sulphate) }\end{array}$ & $\begin{array}{c}\text { UHPLC-MS/MS }\left(\mathrm{ESI}^{+}\right) \\
\text {type of column: } \mathrm{C}_{18} ; \\
\text { mobile phase: gradient aqueous } \\
\text { ammonium formate solution }(\mathrm{pH} \\
\text { 9) } / 0.025 \% \text { ammonia in } \mathrm{MeOH}\end{array}$ & $\begin{array}{l}\text { LOD: } 0.1-0.2 \mathrm{ng} \mathrm{mL} \mathrm{m}^{-1} \\
\text { LOQ: } 0.3-0.6 \mathrm{ng} \mathrm{mL}-1 \\
\text { R: } 90.9-109.5 \% \\
\text { RSD: } 2.0-12.3 \%\end{array}$ & Total content & [92] \\
\hline $\begin{array}{c}\text { BP-1, BP-2, BP-3, } \\
\text { BP-6, BP-8, } \\
\text { 4-OH-BP, THB, AVB }\end{array}$ & Nail & $\begin{array}{l}\text { MAE (20 min, } 1000 \mathrm{~W} \text { of } \\
\text { power })\end{array}$ & $\begin{array}{c}\text { UHPLC-MS/MS }\left(\mathrm{ESI}^{+}\right) \\
\text {type of column: } \mathrm{C}_{18} ; \\
\text { mobile phase: gradient } \\
\text { methanol/water } / 0.1 \% \text { formic acid }\end{array}$ & $\begin{array}{l}\text { LOD: } 0.2-1.5 \mathrm{ng} \mathrm{g}^{-1} \\
\text { LOQ: } 1.0-5.0 \mathrm{ng} \mathrm{g}^{-1} \\
\text { R: } 90.2-112.2 \% \\
\text { RSD: } 0.8-12.3 \%\end{array}$ & Total content & [93] \\
\hline $\begin{array}{c}\text { BP-1, BP-2, BP-3, } \\
\text { BP-6, BP-8, } \\
\text { 4-OH-BP }\end{array}$ & $\begin{array}{l}\text { Placental } \\
\text { tissue }\end{array}$ & $\begin{array}{l}\text { MSPD (solvent: ethyl } \\
\text { acetate) }\end{array}$ & $\begin{array}{c}\text { UHPLC-MS/MS (ESI); } \\
\text { type of column: } \mathrm{C}_{18} ; \\
\text { mobile phase: gradient } 0.1 \% \\
\text { ammoniacal aq solution } / 0.1 \% \\
\text { ammonia in methanol }\end{array}$ & $\begin{array}{c}\text { LOD: } 0.1 \mathrm{ng} \mathrm{g}^{-1} \\
\text { LOQ: } 0.2-0.4 \mathrm{ng} \mathrm{g}^{-1} \\
\text { R: } 95-106 \% \\
\text { RSD: } 4.5-11.8 \%\end{array}$ & Free forms & [94] \\
\hline $\begin{array}{c}\text { BP-1, BP-2, BP-3, } \\
\text { BP-4, } \\
\text { 4-OH-BP }\end{array}$ & $\begin{array}{l}\text { Placental } \\
\text { tissue }\end{array}$ & $\begin{array}{l}\text { SLE (solvent: ethyl } \\
\text { acetate) }\end{array}$ & $\begin{array}{l}\text { LC-MS/MS }\left(\mathrm{ESI}^{-}\right) \\
\text {type of column: } \mathrm{RP}_{18} \\
\text { mobile phase: gradient } \\
\text { methanol/water }\end{array}$ & $\begin{array}{l}\text { LOD: } 0.02-0.36 \mathrm{ng} \mathrm{mL}^{-1} \\
\text { LOQ: } 0.05-1.20 \mathrm{ng} \mathrm{mL}-1 \\
\text { R: } 72-110 \% \\
\text { RSD: } 4-40 \%\end{array}$ & Total content & [95] \\
\hline
\end{tabular}


Table 5. Cont

\begin{tabular}{|c|c|c|c|c|c|c|}
\hline UV Filters & Matrix & Extraction Technique & Analytical Technique & Analytical Performance & Comments & Ref. \\
\hline $\begin{array}{c}\text { BP-1, BP-2, BP-3, } \\
\text { BP-8, 4-OH-BP }\end{array}$ & Saliva & $\begin{array}{l}\text { DLLME (disperser } \\
\text { solvent: acetone; } \\
\text { extraction solvent: } \\
\text { trichloromethane) }\end{array}$ & $\begin{array}{c}\text { LC-MS/MS; } \\
\text { type of column: } \mathrm{C}_{18} \\
\text { mobile phase: gradient } \\
\text { methanol/water }\end{array}$ & $\begin{array}{c}\text { LOD: } 0.01-0.15 \mathrm{ng} \mathrm{mL}^{-1} \\
\text { LOQ: } 0.05-0.40 \mathrm{ng} \mathrm{mL}^{-1} \\
\text { R: no data } \\
\text { RSD: } 1-19 \%\end{array}$ & Total content & [96] \\
\hline $\begin{array}{l}\text { EDP, 3-BC, MBC, } \\
\text { OMC, OC, BP-1, } \\
\text { BP-3, BP-6, BP-8, } \\
\text { 4-OH-BP }\end{array}$ & $\begin{array}{l}\text { Placenta } \\
\text { tissue }\end{array}$ & $\begin{array}{l}\text { UAE (disperser solvent: } \\
\text { methanol; extraction } \\
\text { solvent: anisole; } 3 \text { min of } \\
\text { sonification) }\end{array}$ & $\begin{array}{c}\text { UHPLC-MS/MS; } \\
\text { type of column: } \mathrm{C}_{18} ; \\
\text { mobile phase: gradient } \\
\text { acetonitrile } / 0.25 \% \text { formic acid aq }\end{array}$ & $\begin{array}{l}\text { LOD: } 0.05-0.2 \mu \mathrm{g} \mathrm{kg}^{-1} \\
\text { LOQ: } 0.15-0.5 \mu \mathrm{g} \mathrm{kg}^{-1} \\
\text { R: } 90-112 \% \\
\text { RSD: } 3-15 \%\end{array}$ & Total content & [97] \\
\hline
\end{tabular}

The most popular extraction technique in the case of plasma, serum, or blood samples is liquid-liquid extraction with the use of such organic solvents as acetonitrile $[60,63,86]$, as well as a methyl tert-butyl ether [81,87] (Table 4). Another technique is dispersive liquid-liquid microextraction (DLLME) with the use of acetone as the disperser solvent and trichloromethane as the extraction solvent $[82,83]$ or acetone as the disperser solvent and chloroform as the extraction solvent [45]. Solid-phase extraction with the C18 sorbent $[84,85]$ and fabric phase sorptive extraction (FPSE) [73] have also been employed.

In the case of milk, semen, and silva samples, determination takes place in the same way as for urine and plasma samples, and as such, the first step is the acid or enzymatic hydrolysis [69,88-90]. Afterwards, acetonitrile [88,90], formic acid [56], isopropanol [89], or methanol [91] is added to precipitate proteins. Finally, in the case of other biological samples such as placenta, nail, or epidermal membrane tissue, homogenisation takes place as well. The samples are shaken and mixed to enable tissue break up (Table 5).

The extraction techniques used in the determination of UV filters in milk, semen, and tissue samples are the same as in the case of urine, i.e., solid-phase extraction, in manual mode [56] and online configuration [89,91]; the ultrasound-assisted dispersive solid-phase extraction (USAD-SPE) is employed as well [92]. Microwave-assisted digestion/extraction (MAE) [93], matrix solid-phase dispersion (MSPD) [94], solid-liquid extraction (SLE) [95], dispersive liquid-liquid microextraction [96], and ultrasound-assisted extraction (UAE) [97] have also been applied for this purpose (Table 5).

\subsection{Analytical Techniques}

Even if an exhaustive initial sample treatment is performed to eliminate possible interfering compounds from the sample, an adequate analytical separation technique must still be selected to improve analyte determination. Tables 3-5 present the most used analytical techniques for the detection and quantification of UV filters in biological samples. Liquid chromatography and gas chromatography coupled with MS or MS/MS is the most frequent choice. The choice of either GC or LC is mainly based on the physicochemical properties of the target compounds. GC is usually employed to determinate volatile analytes, whereas LC is applied to quantify both more polar and less volatile compounds.

Liquid chromatography has been used most widely for the determination of UV filters in biological samples. LC coupled with mass spectrometry detectors in tandem is the preferable option. Various ionisation sources have also been used. The most frequently used ionisation mode has been electrospray ionisation (ESI) $[45,46,51,55,59,63-65,81-83,87,90,92,94-97]$. Moreover, it was found that $\mathrm{ESI}^{+}$has better efficiency than $\mathrm{ESI}^{-}$[56]. It is a soft ionisation technique suitable for polar and mildly non-polar compounds. Nevertheless, since ion suppression or improvement in the complex matrix may occur, atmospheric pressure chemical ionisation (APCI) $[47-49,75,77]$ and atmospheric pressure photoionisation (APPI) $[84,85]$ have also been used. In all mentioned cases, the determination was carried by multiple reaction monitoring (MRM) mode of the most intense transition, with another one employed to confirm the presence of UV filters in biological matrices at very low concentration levels. Yet another type of detector coupled to liquid chromatography is based on UV/Vis spectroscopy. It is often used due to the fact that UV filters exhibit a high absorbance in the UV range of the electromagnetic spectrum $[44,52,60,70,75-77,80,86]$. Liquid chromatography coupled with a fluorometric detector has been scarcely used because most UV filters do not 
exhibit fluorescence properties. LC-FL was only used twice-in determining PBSA [71], as well as PEG-25 and PABA [72] in urine samples.

While gas chromatography has been used less often, in most cases it is coupled with mass spectrometry with electron impact $[53,54,62,74,79]$. In the case of UV filters, a derivatisation step is required before the GC analysis. UV filters have been typically derivatized by using such silylating reagents as N,O-Bis (trimethylsilyl) trifluoroacetamide with trimethylchlorosilane (BSTFA-TMCS) [62] or N-methyl-N-(trimethylsilyl) trifluoroacetamide (MSTFA) [54].

Lastly, despite comprehensive sample preparation and the use of carefully select analytical techniques, it must be noted that final results may sometimes be affected by the "matrix effect." This phenomenon may impact quantitative recoveries when using external calibration. As such, it may cause differences in the behaviour of the analytes with the accompanying matrix compounds that one can use to enhance or decrease the signal (e.g., ion suppression in the mass spectrum) or affect the extraction efficiency when the extraction technique is used. This negative effect has been adjusted for by using a matrix-matched calibration (the use of the same matrix without analytes to prepare the standard calibration solutions). In other cases, the standard addition calibration method or an isotopic internal standard was used.

\subsection{Accuracy and Sensitivity}

Tables 3-5 show information about achieved results for different analytical methods used for the determination of UV filters in biological samples.

The analytical methods presented in it resulted in recoveries enabling exhaustive quantification of the target UV filters in the biological matrices, using external or matrixmatched or standard addition calibration. Thus, in the case of urine samples, the greatest recoveries have been achieved for BP-2 (118\%) using microextraction by packed sorbent [78] and for EHS (113\%) using liquid-liquid extraction [63]. In the case of blood, plasma, and serum samples, the best recoveries have been obtained for BP-1 (146.4\%) using liquidliquid extraction [81]. In milk samples, the highest-level recoveries have been achieved for BP-3 (112\%) by using salt-assisted liquid-liquid extraction coupled with dispersive solid-phase extraction [88]. The recoveries in the case of the determination of OMC in placenta tissue by using ultrasound-assisted extraction amounted up to $112 \%$ [97].

In terms of sensitivity, the published methods (Tables 3-5) enable the determination of UV filters in the low $\mathrm{pg} \mathrm{mL}^{-1}$ range.

In the urine samples, the lowest limit of detection (LOD) has been achieved for BP-3 (5 $\mathrm{pg} \mathrm{mL}^{-1}$ ) using hollow-fibre liquid-phase microextraction [42]. The LOD for BP-3, 4MBC, OC, and HS (0.47-0.59 $\mathrm{pg} \mathrm{mL}^{-1}$ ) was obtained by using accelerated solvent extraction coupled with solid-phase extraction [62]. In the plasma sample, the LOD was at a level of $0.8 \mathrm{pg} \mathrm{mL}^{-1}$ for BP; it was determined using liquid-liquid extraction in conjunction with solid-phase extraction [87].

In the milk sample, the best LOD has been achieved for BP- 6 and BP-1 $\left(0.1 \mathrm{ng} \mathrm{mL}^{-1}\right)$ using salt-assisted liquid-liquid extraction coupled with dispersive solid-phase extraction [69]. In the determination of 4-OH-BP in the tissue sample, the LOD of $0.02-10 \mathrm{ng} \mathrm{mL}^{-1}$ has been obtained using solid-liquid extraction [95].

The low levels achieved in the determination of UV filters in biological samples have been influenced by the use of sensitive analytical techniques (e.g., MS/MS), as well as such enrichment techniques as LLE, SPE, MALLE, SPME, SBSE, SDME, HF-LPME, and MALLME.

\section{Conclusions}

Organic UV filters are a family of cosmetic ingredients most widely used in a common variety of cosmetic products to protect consumers from UV solar radiation. Since compounds belonging to this group can be metabolised, excreted, and/or bioaccumulated, 
UV filters may be harmful to the human body. This has made analysing UV filters both in cosmetics products and biological samples a necessity.

Liquid chromatography with MS or UV detection is the dominant method for the determination of UV filters. The large majority of published works used conventional C18 or C8 separation columns. Due to the low level of UV filters in the biological samples (e.g., urine, blood, milk), it is necessary to perform the extraction and clean-up steps before the determination procedure to improve the detection limits. LLE and SPE are the most widely used sample preparation and enrichment methods among all those used. However, these conventional techniques present some drawbacks, such as the consumption of large volumes of sample and often toxic organic solvents, but they are time consuming. Nonetheless, such modern microextraction techniques as MEPS, SPME, SBSE, or DLLME are used as well. However, they are only used in $25 \%$ of analytical procedures. Due to the trends of modern analytical techniques towards "Green Analytical Chemistry," they should in the future replace the classic methods of preparing samples for research. This is because of their many advantages, i.e., time-consuming and labour intensity, and above all because they are solvent-free methods.

This review paid special attention to the analytical performance, e.g., limits of detection, accuracy, and repeatability for developed and validated analytical methods. Organic UV filters have been determined to be prevalent in all kinds of biological matrices and are associated with specific markers connected to metabolism, physiological development, and harmful effects in the human body.

Author Contributions: Conceptualization, I.N. and G.W.; writing—original draft preparation, I.N.; writing-review and ending, I.N. and G.W.; supervision, G.W. All authors have read and agreed to the published version of the manuscript.

Funding: This research received no external funding.

Institutional Review Board Statement: Not applicable.

Informed Consent Statement: Not applicable.

Data Availability Statement: Not applicable.

Conflicts of Interest: The authors declare no conflict of interest.

\begin{tabular}{|c|c|}
\hline$\left[\mathrm{C}_{6} \mathrm{MIM}\right]\left[\mathrm{PF}_{6}\right]:$ & hexyl-3-methylimidazolium hexafluorophosphate \\
\hline 2-OH-BP: & 2-hydroxybenzophenone \\
\hline 3-BC: & 3-benzophenone camphor \\
\hline 4-AHA: & p-aminohippuric acid \\
\hline 4-AMB: & p-acetamidobenzoic acid \\
\hline 4-DHB: & 4,4-dihydroxybenzophenone \\
\hline 4-MBC: & 3-(4-methylbenzylidene)-camphor \\
\hline 4-OCH${ }_{3}-\mathrm{AHA}:$ & p-acetamidohippuric acid \\
\hline 4-OH-BP: & 4-hydroxybenzophenone \\
\hline 5cx-EPS: & 5-(((2-hydroxybenzoyl)oxy)methyl)heptanoic acid \\
\hline 5-OH-EHS: & 5-hydroxy-2-ethylhexyl salicylate \\
\hline 5oxo-EHS: & 2-ethyl-5-oxohexyl 2-hydroxybenzoate \\
\hline AALME: & air-assisted liquid-liquid microextraction \\
\hline Ac: & Acetone \\
\hline APCI: & atmosphere pressure chemical ionisation \\
\hline API: & atmosphere pressure ionisation \\
\hline APPI: & atmosphere pressure photoionisation \\
\hline ASE: & accelerated solvent extraction \\
\hline BMDBM: & butyl methoxydibenzoylmethane/avobenzene \\
\hline $\mathrm{BA} \mu \mathrm{E}:$ & bar adsorptive microextraction \\
\hline
\end{tabular}




\begin{tabular}{|c|c|}
\hline BC: & benzyl cinnamate \\
\hline BDM: & butyl methoxydibenzoylmethane \\
\hline EMT: & bis-ethylhexyloxyphenol methoxyphenyl triazine \\
\hline BP: & Benzophenone \\
\hline BP-1: & 2,4-dihydroxybenzophenone \\
\hline BP-10: & 2-hydroxy-4-methoxy-4'-methylbenzophenone \\
\hline BP-12: & (2-hydroxy-4-octoxy-phenyl)-phenyl-methanone \\
\hline BP-2: & $2,2^{\prime}, 4,4^{\prime}$-tetrahydroxybenzophenone \\
\hline BP-3: & 2-hydroxy-4-methoxybenzophenone \\
\hline BP-4: & 2-hydroxy-4-methoxybenzophenone-5-sulphonic acid \\
\hline BP-6: & $2,2^{\prime}$-dihydroxy-4,4'-dimethoxybenzophenone \\
\hline BP-7: & 5-chloro-2- hydroxybenzophenone \\
\hline BP-8: & 2,2'-dihydroxy-4-methoxybenzophenone \\
\hline BP-OH: & Benzhydrol \\
\hline BS: & benzyl salicate \\
\hline BZT: & Benzotriazole \\
\hline C18: & Octadecyl \\
\hline CDAA: & 2-cyano-3,3-diphenyl acrylic acid \\
\hline CPE: & cloud point extraction \\
\hline DAD: & diode-array detection \\
\hline DART-MS: & direct-analysis-in-real-time mass spectrometry \\
\hline DBT: & diethylhexyl butamino triazone \\
\hline DCM: & Dichloromethane \\
\hline DEA: & Diethylaminopropyl \\
\hline DHHB: & diethyloamino hydroxybenzoyl hexyl benzoate \\
\hline DLLME: & dispersive liquid-liquid microextraction \\
\hline DMF: & n,n-dimethylformamide \\
\hline DTS: & drometrizole trisiloxane \\
\hline DS: & Densitometry \\
\hline d-SPE: & dispersive solid-phase extraction \\
\hline EA: & ethyl acetate \\
\hline ECD: & electron captur detector \\
\hline EDP: & 2-ethylhexyl 4-(n,n-dimethylamino)benzoate \\
\hline EHC: & ethylhexyl cinnamate \\
\hline EHS: & 2-ethylhexyl salicylate \\
\hline EI: & electron impact \\
\hline EMC: & ethylhexyl methoxycinnamate \\
\hline EHS: & ethylhexyl salicylate \\
\hline ESI: & electrospray ionisation \\
\hline ET: & ethylhexyl triazone \\
\hline EtOH: & Ethanol \\
\hline EtPABA: & ethyl p-aminobenzoic acid \\
\hline FL: & Fluorescence \\
\hline FPSE: & fabric phase sorptive extraction \\
\hline GC: & gas chromatography \\
\hline HFLPME: & hollow-fiber liquid-phase microextraction \\
\hline HPLC: & high-performance liquid chromatography \\
\hline HS: & salicylic acid 3,3,5-trimethcyclohexyl ester \\
\hline HTLC: & high-temperature liquid chromatographic \\
\hline IMC: & isoamyl p-methoxycinnamate \\
\hline LC: & liquid chromatography \\
\hline LD: & liquid desorption \\
\hline LLE: & liquid-liquid extraction \\
\hline LOD: & limit of detection \\
\hline $\log _{\mathrm{Ko} / \mathrm{w}}:$ & $\log$ octanol/water partition coefficient \\
\hline LOQ: & limit of quantification \\
\hline LTP-MS: & low temperature plasma ionisation mass spectrometry \\
\hline
\end{tabular}


MA:

MAE:

MBBT:

MBC:

MBP:

$\mathrm{MeCN}$ :

MEKC:

$\mathrm{MeOH}$ :

MEPS:

MMLLE:

MS/MS:

MS:

MSPD:

MTBE:

$\mathrm{NaCl}$ :

OC:

ODP:

ODPABA:

OMC:

OS:

PABA:

PMDSA:

PDA:

PEG-25 PABA:

PHBA:

PLE:

$\mathrm{P}_{\mathrm{Ka}}$

PSA:

QuEChERSExtraction:

$\mathrm{R}$ :

RSD:

SALLE:

SBSE:

SDME:

SFC:

SIA:

SI SPE:

SLE:

SPE:

SPME:

SWV:

TBHPBT:

TCM:

TFA:

TFC:

THB:

TLC:

UAE:

UHPLC:

UHPSFC:

UPLC:

USAD-SPE:

UV/Vis:

VADLLME: menthyl anthranilate

microwave-assisted extraction

methylene bis-benzotriazolyl tetramethyl butyl phenol

4-methylbenzylidene camphor

methylene bis-benzotriazoyl tetramethylbutylphenol

Acetonitrile

micellar electrokinetic capillary chromatography

Methanol

microextraction by packed sorbent

microporous membrane liquid-liquid extraction

tandem mass spectrometry

mass spectrometry

matrix solid phase dispersion

methyl tert-butyl ether

sodium chloride

4-methylbenzilidene camphor/octocrylane

octyl dimethyl PABA

2-ethylhexyl 4-(dimethylamino)benzoate

2-ethylhexyl p-methoxycinnamate

2-ethylhexylsalicylate

p-aminobenzoic acid

2-phenylbenzimidazole-5-sulphonic acid

photodiode-array detection

polyethylene glycol 25 paminobenzoic acid

4-hydroxy benzoic acid

pressurized liquid extraction

acid dissociation constant

primary-secondary amine

Quick, Easy, Cheap, Effective, Rugged, and Safe Extraction

Recovery

relative standard deviation

salt-assisted liquid-liquid extraction

stir bar sorptive extraction

single-drop microextraction

supercritical fluid chromatography

sequential injection analysis

sequential injection solid-phase extraction

solid-liquid extraction

solid-phase extraction

solid-phase microextraction

squarewave voltammetry

2-(5-tert-butyl-2-hydroxyphenyl)benzotriazole

trichloroamine

trifluoroacetic acid

turbulent flow chromatography

2,3,4-trihydroxybenzophenone

thin-layer chromatography

ultrasound-assisted extraction

ultra-high-performance liquid chromatography

ultra-high performance supercritical fluid chromatography

ultra-performance liquid chromatography

ultrasound-assisted dispersive solid phase extraction

ultraviolet/visible spectrometry

vortex-assisted dispersive liquid-liquid microextraction 


\section{References}

1. Matsumura, Y.; Ananthaswamy, H.N. Toxic effects of ultraviolet radiation on the skin. Toxicol. Appl. Pharmacol. 2004, 195, 298-308. [CrossRef] [PubMed]

2. Owens, D.M.; Watt, F.M. Contribution of stem cells and differentiated cells to epidermal tumours. Nat. Rev. Canc. 2003, 3, 444-451. [CrossRef] [PubMed]

3. Astel, A.; Stec, M.; Rykowska, I. Occurrence and distribution of UV filters in beach sediments of the Southern Baltic sea coast. Water 2020, 12, 3024. [CrossRef]

4. Gasparro, F.P.; Mitchnick, M.; Nash, J.F. A review of sunscreen safety and efficacy. Photochem. Photobil. 1998, 68, 243-256. [CrossRef]

5. Pafili, A.; Meikopoulos, T.; Kontogiannidou, E.; Papageorgiou, S.; Demiri, E.; Meimari, D.; Fatouros, D.G.; Gika, H.; Theodoridis, G. Development and validation of LC-MS/MS method for the determination of UV-filters across human skin in vitro. J. Chromatogr. B 2021, 1167, 122561. [CrossRef]

6. Wang, A.; Hu, L.; Liu, J.; Tian, M.; Yang, L. Polyaniline-coated core-shell silica microspheres-based dispersive-solid phase extraction for detection of benzophenone-type UV filters in environmental water samples. Environ. Adv. 2021, 3, 100037. [CrossRef]

7. EC. Regulation (EC) No 1223/2009 of the European Parliament and of the Council of 30 November 2009 on Cosmetic Products. OJ L 2009, 342, 59-209.

8. Chisvert, A.; Salvador, A. UV Filters in Sunscreens and Other Cosmetics. Regulatory Aspects and Analytical Methods. In Personal Care Products, 2nd ed.; Salvador, A., Chisvert, A., Eds.; Elsevier: Amsterdam, The Netherlands, 2018; pp. 85-106.

9. Martín-Pozo, L.; Gomez-Regalado, M.; Moscoso-Ruiz, I.; Zafra-Gomez, A. Analytical methods for the determination of endocrine discrupting chemicals in cosmetics and personal care products: A review. Talanta 2021, 234, 122642. [CrossRef]

10. Chisvert, A.; Tarazona, I.; Salvador, A. A reliable and environmentally-friendly liquid-chromatographic method for multi-class determination of fat-soluble UV filters in cosmetic products. Anal. Chim. Acta 2013, 790, 61-67. [CrossRef] [PubMed]

11. Giokas, D.L.; Salvador, A.; Chisvert, A. UV filters: From sunscreens to human body and the environment. Trends Anal. Chem. 2007, 26, 360-374. [CrossRef]

12. Lores, M.; Llampart, M.; Alvarez-Rivera, G.; Guerra, E.; Vila, M.; Celeiro, M.; Lamas, J.P.; Garcia-Jares, C. Positive lists of cosmetic ingredients: Analytical methodology for regulatory and safety controls-A review. Anal. Chim. Acta 2016, 915, 1-26. [CrossRef] [PubMed]

13. De Orsi, D.; Giannini, G.; Gagliardi, L.; Porrà, R.; Berri, S.; Bolasco, A.; Carpani, I.; Tonelli, D. Simple Extraction and HPLC determination of UV-A and UV-B filters in sunscreen products. Chromatographia 2006, 64, 509-515. [CrossRef]

14. Wu, Y.W.; Jiang, Y.Y.; Liu, J.F.; Xiong, K. Cloud point extraction combined with micellar electrokinetic capillary chromatography determination of benzophenones in cosmetic matrix. Electrophoresis 2008, 29, 819-826. [CrossRef]

15. Liu, T.; Wu, D. Simultaneous determination of some ultraviolet-absorbing chemicals in sunscreen cosmetics using a highperformance liquid chromatography method. Int. J. Cosmet. Sci. 2011, 33, 408-415. [CrossRef]

16. Nyeborg, M.; Pissavini, M.; Lemasson, Y.; Doucet, O. Validation of HPLC method for the simultaneous and quantitative determination of 12 UV-filters in cosmetics. Int. J. Cosmet. Sci. 2010, 32, 47-53. [CrossRef] [PubMed]

17. Haunschmidt, M.; Buchberger, W.; Klampfl, C.W.; Hertsens, R. Identification and semi-quantitative analysis of parabens and UV filters in cosmetic products by direct-analysis-in-real-time mass spectrometry and gas chromatography with mass spectrometric detection. Anal. Methods 2011, 3, 99-104. [CrossRef] [PubMed]

18. Kim, K.; Mueller, J.; Park, H.R.; Kang, S.H.; Yoon, M.H.; Lee, J.B. Simultaneous Determination of nine UV filters and four preservatives in suncare products by High-Performance Liquid Chromatography. J. Chromatogr. Sci. 2011, 49, 554-559. [CrossRef]

19. Yang, H.Y.; Li, H.F.; Ito, M.; Lin, J.M.; Guo, G.S.; Ding, M.Y. Combination of dynamic hollow fiber liquid-phase microextraction with HPLC analysis for the determination of UV filters in cosmetic products. Sci. China Chem. 2011, 10, 1627-1634. [CrossRef]

20. Júnior, J.B.G.; Araujo, T.A.; Trindade, M.A.G.; Ferreira, V.S. Electroanalytical determination of the sunscreen agent octocrylene in cosmetic products. Int. J. Cosmet. Sci. 2012, 34, 91-94. [CrossRef]

21. Yousef, A.N.; Haidar, S.; Al.-Khayat, M.A. Development and validation of RP-HPLC method for analysis of four UV filters in sunscreen products. Int. J. Pharm. Sci. Rev. Res. 2013, 23, 254-258.

22. Kale, S.; Kulkarni, K.; Ugale, P.; Jadav, K. Application of HPTLC for the qualitative and quantitative analysis of avobenzone, oxybenzone, octinoxate in sunscreen cream. Int. J. Pharm. Pharm. Sci. 2014, 6, 391-394.

23. Chang, N.I.; Yoo, M.; Lee, S. Determination of fourteen sunscreen agents in cosmetics using high-performance liquid chromatography. Int. J. Cosmet. Sci. 2015, 37, 175-180. [CrossRef]

24. Lopez-Gazpio, J.; Garcia-Arrona, R.; Millán, E. Simultaneous determination of multiclass preservatives including isothiazolinones and benzophenone-type UV filters in household and personal care products by micellar electrokinetic chromatography. Electrophoresis 2015, 36, 1064-1072. [CrossRef] [PubMed]

25. Hsiao, W.Y.; Jiang, S.J.; Feng, C.H.; Wang, S.W.; Chen, Y.L. Determining ultraviolet absorbents in sunscreen products by combining direct injection with micelle collapse on-line preconcentration capillary electrophoresis. J. Chromatogr. A 2015, 1383, 175-181. [CrossRef]

26. Wharton, M.; Geary, M.; O'Connor, N.; Curtin, L.; Ketcher, K. Simultaneous liquid chromatographic determination of 10 ultra-violet filters in sunscreens. J. Chromatogr. Sci. 2015, 53, 1289-1295. [CrossRef] [PubMed] 
27. Ma, T.; Li, Z.; Niu, Q.; Li, Y.; Zhou, W. Double dispersant-assisted ionic liquid dispersive liquid-liquid microextraction coupled with capillary electrophoresis for the determination of benzophenone-type ultraviolet filters in sunscreen cosmetic product. Electrophoresis 2015, 36, 2530-2537. [CrossRef] [PubMed]

28. Ding, X.; Gerbig, S.; Spengler, B.; Schulz, S. Reactive low temperature plasma ionization mass spectrometry for the determination of organic UV filters in personal care products. Talanta 2018, 178, 780-787. [CrossRef]

29. Meng, X.; Ma, Q.; Bai, H.; Wang, Z.; Han, C.; Wang, C. Simultaneous separation and determination of 15 organic UV filters in sunscreen cosmetics by HPLC-ESI-MS/MS. Int. J. Cosmet. Sci. 2016, 39, 386-392. [CrossRef] [PubMed]

30. Khalikova, M.A.; Leselllier, E.; Chapuzet, E.; Satínský, D.; West, C. Development and validation of ultra-high performance supercritical fluid chromatography method for quantitative determination of nine sunscreens in cosmetic samples. Anal. Chim. Acta 2018, 1034, 184-194. [CrossRef]

31. Lu, S.; Long, F.; Lu, P.; Lei, B.; Jiang, Z.; Liu, G.; Hang, J.; Ma, S.; Yu, Y. Benzophenone-UV filters in personal care products and urine of schoolchildren from Shenzhen, China: Exposure assessment and possible source. Sci. Total Environ. 2018, 640-641, 1214-1220. [CrossRef]

32. Zhou, W.; Wang, P.G.; Wittenberg, J.B.; Rua, D.; Krynitsky, A.J. Simultaneous determination of cosmetics ingredients in nail products by fast gas chromatography with tandem mass spectrometry. J. Chromatogr. A 2016, 1446, 134-140. [CrossRef] [PubMed]

33. Liao, F.Y.; Su, Y.L.; Weng, J.R.; Lin, Y.C.; Feng, C.H. Ultrasound-vortex-assisted dispersive liquid-liquid microextraction combined with high performance liquid chromatography-diode array detection for determining UV filters in cosmetics and the human stratum corneum. Molecules 2020, 25, 4642. [CrossRef]

34. Imamović, B.; Šober, M.; Beĉić, E. Identification and determination butylmethoxydibenzoylmethane in the presence benzophenone3 and ethylhexylmethoxycinnamate in suncare preparation. Int. J. Cosmet. Sci. 2009, 31, 383-389. [CrossRef]

35. Vila, M.; Lamas, J.P.; Garcia-Jares, C.; Dagnac, T.; Llompart, M. Optimization of an analytical methodology for the simultaneous determination of different classes of ultraviolet filters in cosmetics by pressurized liquid extraction-gas chromatography tandem mass spectrometry. J. Chromatogr. A 2015, 1405, 12-22. [CrossRef]

36. Sobańska, A.W.; Pyzowski, J. Quantification of sunscreen ethylhexyl triazone in topical skin-care products by Normal-Phase TLC/Densitometry. Sci. World J. 2012, 807516, 1-6. [CrossRef]

37. Kapalavavi, B.; Marple, R.; Gamsky, C.; Yang, Y. Separation of sunscreens in skincare creams using greener high-temperature liquid chromatography and subcritical water chromatography. Int. J. Cosmet. Sci. 2012, 34, 169-175. [CrossRef]

38. Vila, M.; Facorro, R.; Lamas, J.P.; Garcia-Jares, C.; Dagnac, T.; Llompart, M. Determination of fifteen water and fat-soluble UV filters in cosmetics by pressurized liquid extraction followed by liquid chromatography tandem mass spectrometry. Anal. Methods 2016, 8, 6787-6794. [CrossRef]

39. Cadena-Aizaga, M.I.; Montedeoca-Esponda, S.; Torres-Padrón, M.E.; Sosa-Ferrera, Z.; Santa Rodriguez, J.J. Organic UV filters in marine environments: An update of analytical methodologies, occurrence and distribution. Trends Environ. Anal. Chem. 2020, 25, e00079. [CrossRef]

40. Dencausse, I.; Galland, A.; Clamou, J.L.; Basso, J. Validation of HPLC method for quantitative determination of Tinosorb ${ }^{\circledR}$ S and three other sunscreens in a high protection cosmetic product. Int. J. Cosmet. Sci. 2008, 30, 373-382. [CrossRef] [PubMed]

41. Sobańska, A.W.; Kałębasiak, K.; Pyzowski, J.; Brzezińska, E. Quantification of sunscreen Benzophenone-4 in hair shampoos by hydrophilic interactions Thin-Layer Chromatography/Densitometry or derivative UV spectrophotometry. J. Anal. Methods Chem. 2015, 2015, 1-7. [CrossRef] [PubMed]

42. Lesellier, E.; Mith, D.; Dubrulle, I. Method developments approaches in supercritical fluid chromatography applied to the analysis of cosmetics. J. Chromatogr. A 2015, 1423, 158-168. [CrossRef] [PubMed]

43. Jiménez-Díaz, I.; Zafra-Gómez, A.; Ballesteros, O.; Navalón, A. Analytical methods for the determination of personal care products in human samples: An overview. Talanta 2014, 129, 448-458. [CrossRef]

44. Gonzalez, H.G.; Farbrot, A.; Larkö, O. Percutaneous absorption of benzophenone-3, a common component of topical sunscreens. Clin. Exp. Dermatol. 2002, 27, 691-694. [CrossRef]

45. Tarazona, I.; Chisvert, A.; Salvador, A. Determination of benzophenone-3 and its main metabolites in human serum by dispersive liquid-liquid microextraction followed by liquid chromatography tandem mass spectrometry. Talanta 2013, 116, 388-395. [CrossRef]

46. Dewalquea, L.; Pirarda, C.; Dubois, N.; Charlier, C. Simultaneous determination of some phthalate metabolites, parabens and benzophenone-3 in urine by ultra-high pressure liquid chromatography tandem mass spectrometry. J. Chromatogr. B 2014, 949-950, 37-47. [CrossRef] [PubMed]

47. Ye, X.; Kuklenyik, Z.; Needham, L.L.; Calafat, A.M. Automated On-Line Column-Switching HPLC-MS/MS Method with Peak Focusing for the Determination of Nine Environmental Phenols in Urine. Anal. Chem. 2005, 77, 5407-5413. [CrossRef]

48. Ye, X.; Kuklenyik, Z.; Needham, L.L.; Calafat, A.M. Quantification of urinary conjugates of bisphenol A, 2,5-dichlorophenol, and 2hydroxy-4-methoxybenzophenone in humans by online solid phase extraction-high performance liquid chromatography-tandem mass spectrometry. Anal. Bioanal. Chem. 2005, 383, 638-644. [CrossRef]

49. Ye, X.; Bishop, A.M.; Reidy, J.A.; Needham, L.L.; Calafat, A.M. Temporal stability of the conjugated species of bisphenol A, parabens, and other environmental phenols in human urine. J. Expo. Sci. Environ. Epidemiol. 2007, 17, 567-572. [CrossRef]

50. Gavin, Q.W.; Ramage, R.T.; Waldman, J.M.; She, J. Development of HPLC-MS/MS method for the simultaneous determination of environmental phenols in human urine. Int. J. Environ. Anal. Chem. 2014, 94, 168-182. [CrossRef] 
51. Asimakopoulos, A.G.; Wanga, L.; Thomaidis, N.S.; Kannan, K. A multi-class bioanalytical methodology for the determination of bisphenol A diglycidyl ethers, p-hydroxybenzoic acid esters, benzophenone-type ultraviolet filters, triclosan, and triclocarban in human urine by liquid chromatography-tandem mass spectrometry. J. Chromatogr. A 2014, 1324, 141-148. [PubMed]

52. Vidal, L.; Chisvert, A.; Canals, A.; Salvador, A. Sensitive determination of free benzophenone-3 in human urine samples based on an ionic liquid as extractant phase in single-drop microextraction prior to liquid chromatography analysis. J. Chromatogr. A 2007, 1174, 95-103. [CrossRef] [PubMed]

53. Kawaguchi, M.; Ito, R.; Honda, H.; Endo, N.; Okanouchi, N.; Saito, K.; Seto, Y.; Nakazawa, H. Measurement of Benzophenones in Human Urine Samples by Stir Bar Sorptive Extraction and Thermal Desorption-Gas Chromatography-Mass Spectrometry. Anal. Sci. 2008, 24, 1509-1512. [CrossRef]

54. Kawaguchi, M.; Ito, R.; Honda, H.; Koganei, Y.; Okanouchi, N.; Saito, K.; Seto, Y.; Nakazawa, H. Miniaturized hollow fiber assisted liquid-phase microextraction and gas chromatography-mass spectrometry for determination of benzophenone and derivates in human urine sample. J. Chromatogr. B 2009, 877, 298-302. [CrossRef] [PubMed]

55. Kunisue, T.; Wu, Q.; Tanabe, S.; Aldous, K.M.; Kannan, K. Analysis of five benzophenone-type UV filters in human urine by liquid chromatography-tandem mass spectrometry. Anal. Methods 2010, 2, 707-713. [CrossRef]

56. León, Z.; Chisvert, A.; Tarazona, I.; Salvador, A. Solid-phase extraction liquid chromatography-tandem mass spectrometry analytical method for the determination of 2-hydroxy-4-methoxybenzophenone and its metabolites in both human urine and semen. Anal. Bioanal. Chem. 2010, 398, 831-843. [CrossRef] [PubMed]

57. Kunisue, T.; Chen, Z.; Buck Louis, G.M.; Sundaram, R.; Hediger, M.L.; Sun, L.; Kannan, K. Urinary concentrations of Benzophenone-type UV Filters in U.S. women and their association with endometriosis. Environ. Sci. Technol. 2012, 46, 4624-4632. [CrossRef] [PubMed]

58. Frederiksen, H.; Nielsen, O.; Skakkebaek, N.E.; Juul, A.; Andersson, A.M. UV filters analyzed by isotope diluted TurboFlow-LCMS/MS in urine from Danish children and adolescents. Int. J. Hyg. Environ. Health 2016, 12967, 1-10. [CrossRef] [PubMed]

59. León-González, Z.; Ferreiro-Vera, C.; Priego-Capote, F.; Luque de Castro, M.D. Targeting metabolomics analysis of the sunscreen agent 2-ethylhexyl 4-(N,N-dimethylamino)benzoate in human urine by automated on-line solid-phase extraction-liquid chromatography-tandem mass spectrometry with liquid chromatography-time-of-flight/mass spectrometry confirmation. $J$. Chromatogr. A 2011, 1218, 3013-3021.

60. Sarveiya, V.; Risk, S.; Benson, H.A.E. Liquid chromatographic assay for common sunscreen agents: Application to in vivo assessment of skin penetration and systemic absorption in human volunteers. J. Chromatogr. B 2004, 803, 225-231. [CrossRef] [PubMed]

61. Adoamnei, E.; Mendiola, J.; M oñino-García, M.; Vela-Soria, F.; Iribarne-Durán, L.M.; Fernández, M.F.; Olea, N.; Jørgensen, N.; Swan, S.H.; Torres-Cantero, A.M. Urinary concentrations of benzophenone-type ultra violet light filters and reproductive parameters in young men. Int. J. Hyg. Environ. Health 2018, 221, 531-540. [CrossRef]

62. Ao, J.; Yuan, T.; Gu, J.; Ma, Y.; Shen, Z.; Tian, Y.; Shi, R.; Zhou, W.; Zhang, J. Organic UV filters in indoor dust and human urine: A study of characteristics, sources, associations and human exposure. Sci. Total Environ. 2018, 640-641, 1157-1164. [CrossRef]

63. Klotz, K.; Hof, K.; Hiller, J.; Göen, T.; Drexler, H. Quantification of prominent organic UV filters and their metabolites in human urine and plasma samples. J. Chromatogr. B 2019, 1125, 1-8. [CrossRef]

64. Bury, D.; Brüning, T.; Koch, H.M. Determination of metabolites of the UV filter 2-ethylhexyl salicylate in human urine by online-SPE-LC-MS/MS. J. Chromatogr B 2019, 1110-1111, 59-66. [CrossRef]

65. Chang, F.K.; Shiea, J.; Tsai, H.J. Urinary concentrations of triclosan, benzophenone-3, and bisphenol a in Taiwanese children and adolescents. Int. J. Environ. Research Pub. Health 2017, 14, 1545. [CrossRef]

66. Zhao, H.; Li, J.; Ma, X.; Huo, W.; Xu, S.; Cai, Z. Simultaneous determination of bisphenols, benzophenones and parabens in human urine by using UHPLC-TQMS. Chin. Chem. Lett. 2018, 29, 102-106. [CrossRef]

67. Zuccherato Bocato, M.; Aparecida Cesila, C.; Favero Lataro, B.; de Oliveira, A.R.M.; Dobal Campíglia, A.; Barbosa Jr, F. A fast-multiclass method for the determination of 21 endocrine disruptors in human urine by using vortex-assisted dispersive liquid-liquid microextraction (VADLLME) and LC-MS/MS. Environ. Res. 2020, 189, 109883. [CrossRef]

68. Rocha, B.A.; de Oliveira, A.R.M.; Barbosa, F. A fast and simple air-assisted liquid-liquid microextraction procedure for the simultaneous determination of bisphenols, parabens, benzophenones, triclosan, and triclocarban in human urine by liquid chromatography-tandem mass spectrometry. Talanta 2018, 183, 94-101. [CrossRef]

69. Wang, L.H.; Huang, W.S.; Tai, H.M. Simultaneous determination of p-aminobenzoic acid and its metabolites in the urine of volunteers, treated with p-aminobenzoic acid sunscreen formulation. J. Pharm. Biomed. Anal. 2007, 43, 1430-1436. [CrossRef] [PubMed]

70. Gonzalez, H.; Jacobson, C.E.; Wennberg, A.M.; Larkö, O.; Farbrot, A. Solid-Phase Extraction and Reverse-Phase HPLC: Application to Study the Urinary Excretion Pattern of Benzophenone-3 and its Metabolite 2,4-Dihydroxybenzophenone in Human Urine. Anal. Chem. Insights 2008, 3, 1-7. [CrossRef]

71. Vidal, M.T.; Chisvert, A.; Salvador, A. Sensitive sequential-injection system for the determination of 2-phenylbenzimidazole-5sulphonic acid in human urine samples using on-line solid-phase extraction coupled with fluorimetric detection. Talanta 2003, 59, 591-599. [CrossRef] 
72. Balaguer, A.; Chisvert, A.; Salvador, A.; Herraez, M.; Diez, O. A solid-phase extraction and size-exclusion liquid chromatographic method for polyethylene glycol 25 p-aminobenzoic acid determination in urine: Validation for urinary excretion studies of users of sunscreens. Anal. Chim. Acta 2008, 611, 220-225. [CrossRef]

73. Locatelli, M.; Furton, K.G.; Tartaglia, A.; Sperandio, E.; Ulusoy, H.I.; Kabir, A. An FPSE-HPLC-PDA method for rapid determination of solar UV filters in human whole blood, plasma and urine. J. Chromatogr. B 2019, 1118-1119, 40-50. [CrossRef]

74. March, J.G.; Palou, J.; Chisvert, A.; Salvador, A. A simple novel configuration for in-vial microporous membrane liquid-liquid extraction. J. Chromatogr. A 2009, 1216, 5160-5163. [CrossRef]

75. León, Z.; Chisvert, A.; Balaguer, Á.; Salvador, A. Development of a fully automated sequential injection solid-phase extraction procedure coupled to liquid chromatography to determine free 2-hydroxy-4-methoxybenzophenone and 2-hydroxy-4methoxybenzophenone-5-sulphonic acid in human urine. Anal. Chim. Acta 2010, 664, 178-184. [CrossRef] [PubMed]

76. Almeida, C.; Stepkowska, A.; Alegre, A.; Nogueira, J.M.F. Determination of trace levels of benzophenone-type ultra-violet filters in real matrices by bar adsorptive micro-extraction using selective sorbent phases. J. Chromatogr. A 2013, 1311, 1-10. [CrossRef]

77. Vosough, M.; Mojdehi, N.R.; Salemi, A. Chemometrics assisted dispersive liquid-liquid microextraction for quantification of seven UV filters in urine samples by HPLC-DAD. J. Sep. Sci. 2012, 35, 3575-3585. [CrossRef] [PubMed]

78. Sanglard Silveira, R.; Rocha, B.A.; Rodrigues, J.L.; Barbosa Jr., F. Rapid, sensitive and simultaneous determination of 16 endocrine disrupting chemicals (parabens, benzophenones, bisphenols, and triclocarban) in human urine based on microextraction by packed sorbent combined with liquid chromatography tandem mass spectrometry (MEPS-LC-MS/MS). Chemosphere 2020, $240,124951$.

79. Felix, T.; Hall, B.J.; Brodbelt, J.S. Determination of benzophenone-3 and metabolites in water and human urine by solid-phase microextraction and quadrupole ion trap GC-MS. Anal. Chim. Acta 1998, 371, 195-203. [CrossRef]

80. Fresco-Cala, B.; Cárdenas, S. Nanostructured hybrid monolith with integrated stirring for the extraction of UV-filters from water and urine samples. Talanta 2018, 182, 391-395. [CrossRef] [PubMed]

81. Sunyer-Caldúa, A.; Peiróa, A.; Díaz, M.; Ibáñez, L.; Gago-Ferreroa, P.; Diaz-Cruz, M.S. Development of a sensitive analytical method for the simultaneous analysis of Benzophenone-type UV filters and paraben preservatives in umbilical cord blood. MethodsX 2021, 8, 1-13.

82. Iribarne-Durán, L.M.; Domingo-Piñar, S.; Peinado, F.M.; Vela-Soria, F.; Jimènez-Díaz, I.; Barranco, E.; Olea, N.; Freire, C.; Artacho-Cordón, F.; Ocón-Hernández, O. Menstrual blood concentrations of parabens and benzophenones and related factors in a sample of Spanish women: An exploratory study. Environ. Res. 2020, 183, 1-7. [CrossRef]

83. Vela-Soria, F.; Ballesteros, O.; Zafra-Gómez, A.; Ballesteros, L.; Navalón, A. A new method for the determination of benzophenoneUV filters in human serum samples by dispersive liquid-liquid microextraction with liquid chromatography-tandem mass spectrometry. Talanta 2014, 121, 97-104. [CrossRef]

84. Ye, X.; Wong, L.Y.; Jia, L.T.; Needham, L.L.; Calafat, A.M. Stability of the conjugated species of environmental phenols and parabens in human serum. Environ. Int. 2009, 35, 1160-1163. [CrossRef]

85. Ye, X.; Tao, L.J.; Needham, L.L.; Calafat, A.M. Automated on-line column-switching HPLC-MS/MS method for measuring environmental phenols and parabens in serum. Talanta 2008, 76, 865-871. [CrossRef] [PubMed]

86. Teglia, C.M.; Santamaría, C.G.; Rodriguez, H.A.; Culzoni, M.J.; Goicoechea, H.C. Determination of 2-hydroxy-4-methoxybenzophenone in mice serum and human plasma by ultra-high-performance liquid chromatography enhanced by chemometrics. $M i-$ crochem. J. 2019, 148, 35-41. [CrossRef]

87. Li, J.; Zhang, X.; Mu, Y.; He, Y.; Qiu, T.; Li, W.; Zeng, L. Determination of 21 photoinitiators in human plasma by using highperformance liquid chromatography coupled with tandem mass spectrometry: A systemically validation and application in healthy volunteers. J. Chromatogr. A 2021, 1643, 462079. [CrossRef] [PubMed]

88. Vela-Soria, F.; Iribarne-Durán, L.M.; Mustieles, V.; Jimènez-Diaz, I.; Fernández, M.F.; Olea, N. QuEChERS and ultra-high performance liquid chromatography- tandem mass spectrometry method for the determination of parabens and ultraviolet filters in human milk samples. J. Chromatogr. A 2018, 1546, 1-9. [CrossRef]

89. Ye, X.; Kuklenyik, Z.; Needham, L.L.; Calafat, A.M. Measuring environmental phenols and chlorinated organic chemicals in breast milk using automated on-line column-switching-high performance liquid chromatography-isotope dilution tandem mass spectrometry. J. Chromatogr. B 2006, 831, 110-115. [CrossRef]

90. Molins-Delgado, D.; del Mar Olmo-Commpos, M.; Valeta-Juan, G.; Pleguezuelos-Hernández, V.; Barcelo, D.; Díaz-Cruz, M.S. Determination of UV filters in human breast milk using turbulent flow chromatography and babies' daily intake estimation. Environ. Res. 2018, 161, 532-539. [CrossRef]

91. Ye, X.; Bishop, A.M.; Needham, L.L.; Calafat, A.M. Automated on-line column-switching HPLC-MS/MS method with peak focusing for measuring parabens, triclosan, and other environmental phenols in human milk. Anal. Chim. Acta 2008, 622, 150-156. [CrossRef]

92. Rodríguez-Gómez, R.; Zafra-Gómez, A.; Dorival-García, N.; Ballesteros, O.; Navalón, A. Determination of benzophenoneUV filters in human milk samples using ultrasound-assisted extraction and clean-up with dispersive sorbents followed by UHPLC-MS/MS analysis. Talanta 2015, 134, 657-664. [CrossRef] [PubMed]

93. Martín-Pozo, L.; del Carmen Gómez-Regalado, M.; Cantarero-Malagón, S.; Navalón, A.; Zafra-Gómez, A. Determination of ultraviolet filters in human nails using an acid sample digestion followed by ultra-high performance liquid chromatography mass spectrometry analysis. Chemosphere 2021, 273, 128603. [CrossRef] 
94. Vela-Soria, F.; Rodríguez, I.; Ballesteros, O.; Zafra-Gómez, A.; Ballesteros, L.; Cela, R.; Navalón, A. Simplified matrix solid phase dispersion procedure for the determination of parabens and benzophenone-ultraviolet filters in human placental tissue samples. J. Chromatogr. A 2014, 1371, 39-47. [CrossRef] [PubMed]

95. Valle-Sistac, J.; Molins-Delgado, D.; Díaz, M.; Ibáñez, L.; Barceló, D.; Díaz-Cruz, M.S. Determination of parabens and benzophenone-type UV filters in human placenta. First description of the existence of benzyl paraben and benzophenone-4. Environ. Int. 2016, 88, 243-249. [CrossRef] [PubMed]

96. De Oliveira, M.L.; Rocha, B.A.; De Oliviera Souza, V.C.; Barbosa, F. Determination of 17 potential endocrine-disrupting chemicals in human saliva by dispersive liquid-liquid microextraction and liquid chromatography tandem mass spectrometry. Talanta 2019, 196, 271-276. [CrossRef] [PubMed]

97. Vela-Soria, F.; Gallardo-Torres, M.E.; Ballesteros, O.; Díaz, C.; Pèrez, J.; Navalón, A.; Fernández, M.F.; Olea, N. Assessment of parabens and ultraviolet filters in human placenta tissue by ultrasound-assisted extraction and ultra-high performance liquid chromatography-tandem mass spectrometry. J. Chromatogr. A 2017, 1487, 153-161. [CrossRef] [PubMed] 